This work is licensed under a Creative Commons Attribution 4.0 International License.

Ovaj rad dostupan je za upotrebu pod međunarodnom licencom Creative Commons Attribution 4.0.

\title{
GRAFETIČKA I GRAFEMATIČKA OBILJEŽJA PROTESTANTSKE SPOVIDI (1564) U KONTEKSTU HRVATSKOGA KNJIŽEVNOG JEZIKA 16. STOLJEĆA
}

dr. sc. Vera Blažević Krezić, Sveučilište Josipa Jurja Strossmayera u Osijeku, Filozofski fakultet, vblazevic1@ffos.hr, Osijek

izvorni znanstveni članak

UDK 811.163.42(091)“15“

$003.349 .1(497.5)$

rukopis primljen: 7. lipnja 2019; prihvaćen za tisak: 2. listopada 2019.

U radu se ispituju grafetičke i grafematičke odlike glagoljičnoga i latiničnoga izdanja protestantske Spovidi (1564). Izdvojena pitanja grafemsko-fonološkoga sloja - poput bilježenja jerovskih znakova, jata $i$ đerva - razmatraju se u usporedbi sa stanjem zatečenim u starijim protestantskim izdanjima (Postila, Artikuli), kao prilog boljemu poznavanju protestantske književnojezične stilizacije i općih smjernica koje su zacrtale razvoj hrvatskoga književnog jezika u 16. stoljeću.

Ključne riječi: hrvatsko-uraška protestantska tiskara; 16. stoljeće; Spovid (glagoljica i latinica, 1564); grafetika i grafematika

\section{Uvod}

Prebrojavanjem i analizom naslova objavljenih u uraško-hrvatskoj i regensburškoj protestantskoj tiskari (1561-1565/1568) filološki su znanstvenici, tijekom posljednjih triju stoljeća, ustvrdili da je ondje objavljeno najviše glagoljičnih djela (13/14) te da ih u stopu prate ćirilični (8) i latinični 
tekstovi (9) (usp. Jembrih 2013: 524; Damjanović 2014: 50; Kuštović 2016: 238). Kada se temeljnim brojčanim (i pismovnim) podacima protestantske izdavačke / tiskarske djelatnosti pridruže jezična zapažanja, filološka analiza uspijeva razotkriti posebnu vrst šesnaestostoljetnoga književnog jezika, ustanovljenu u razdoblju velikoga ranonovovjekovnog previranja i dezintegracije (Damjanović 2014: 46-52), odnosno oblikovanja pokrajinskih književnih jezika - čakavskoga, kajkavskoga i štokavskoga - uglavnom unutar latiničnoga sociolingvističkog kompleksa koji, još od srednjega vijeka, supostoji s crkvenoslavensko-glagoljičnim (usp. Corin 1993: 155-196; Eterović 2017: 23-25), a oba su podvrgnuta korjenitim promjenama ulaskom u novovjekovnu stvarnost. ${ }^{1}$

Hrvatski crkvenoslavenski jezik krajem 15. i tijekom 16. stoljeća postaje funkcionalno ograničen pa svoju primjenu pronalazi u liturgijskim tekstovima namijenjenima hrvatskim glagoljaškim župama, mahom smještenima u ruralnim hrvatskim predjelima. ${ }^{2}$ Novovjekovno smanjivanje udjela glagoljaštva pospješuju dobro znane društvene, kulturno-političke i crkvene prilike među kojima valja istaknuti odluke Tridentskoga koncila i nastupajuće razdoblje istočnoslavenizacije (rusifikacije) ${ }^{3}$ hrvatskoglagoljskih liturgijskih knjiga (usp. Fućak 1975: 99; Gadžijeva i sur. 2014: 19). Ne treba, međutim, s uma smetnuti činjenicu da se i taj tip književnoga (liturgijskoga) jezika, mada funkcionalno i geografski ograničen, otvarao novovjekovnim zahtjevima demokratizacije knjige, zbog čega se vodilo računa o njegovoj razumljivosti i funkcionalnosti, što sasvim zorno

$1 \mathrm{Za}$ potrebe je ovoga rada dovoljno podsjetiti na šesnaestostoljetnu razgradnju srednjovjekovne hrvatske sociolingvističke podloge koju odlikuje latinsko-hrvatski bilingvizam s crkvenoslavensko-hrvatskom diglosijom (i triglosijom) (vidi: Mihaljević 2010: 229-238; Barbarić 2017: 31-42).

2 Obično se ističe da je glagoljaštvo kao kulturna pojava ozbiljnije zahvatilo samo tri gradska centra: Modruš, Senj i Rijeku (usp. Tandarić 1993: 71, 87; Barbarić 2017: 42). U obzir bi svakako valjalo uzeti i Zadar, inače zanimljiv zbog odnosa prema ikavštini.

3 Slovenska znanstvenica Vanda Babič ukazala je na neprimjerenost termina rusifikacija, odnosno ruska, ruskoslovenska, rusinska/rutenska/ukrajinska redakcija crkvenoslavenskoga jezika. Baveći se analizom procesa koji je u 17. i 18. stoljeću zahvatio hrvatskoglagoljske liturgijske knjige, nazvala ga je istočnoslavenizacijom - i to stoga što je podrazumijevao pravopisnu i jezičnu (mahom fonološku) reformu naših misalskih i brevijarskih tekstova, utemeljenu na onodobnim crkvenoslavenskim gramatikama istočnoslavenskoga (današnjega ukrajinskog) područja: gramatici Lavrentija Zizanija iz 1596, odnosno Meletija Smotrickoga iz 1619. (razdoblje tzv. drugoga južnoslavenskog utjecaja) (usp. Babič 1999: 255, 2000: 36-38, 80). 
pokazuje književnojezična koncepcija modruško-krbavskoga biskupa Šimuna Kožičića Benje (Žagar 2015: 14, 20). ${ }^{4}$ Razvoj je jednoga od triju spomenutih regionalnih književnih jezika dominantno vezan za glagoljaški krug. Filološki ga stručnjaci imenuju čakavskim književnim jezikom sjeverozapadnoga / kajkavsko-sjevernočakavskoga podneblja (Brozović 1978: 9-83; Kapetanović 2011: 77-123; Damjanović 2014: 46, Eterović 2017: 24-26). Unutar njega zamijećeno je i kajkavsko naslojavanje koje doduše nastupa još početkom 15. stoljeća, a zahvaća neliturgijske tekstove zborničkoga karaktera (Malić 1980: 148-150; Damjanović 2008: 138-167). Sličan će tip modeliranja književnoga jezika, utemeljen na knjiškoj (crkvenoslavenskoj) tradiciji i vernakularnoj (prije svega čakavskoj) pismenosti, odnosno jezičnomu blagu crpljenu izravno iz narodnih govora, nastaviti razvijati hrvatski protestanti, a s njihovim su se nastojanjima nerijetko uspoređivali postupci tzv. ozaljskoga književnojezičnog kruga. ${ }^{5}$ Nadalje, čakavski književni jezik 16. stoljeća usporedo se razvija unutar humanističko-renesansnoga jugoistočnog ili štokavsko-južnočakavskog kruga (Zadar - Split - otoci: Hvar / Korčula), dok afirmacija štokavskoga književnog jezika prati uspon Dubrovačke Republike, a ostvaruje se latiničnim i ćiriličnim pismom (usp. Vulić 2011: 125-187; Tafra 2011: 36; Žagar 2013b: 344). Iako je glavnina bosanskohercegovačkih, dalmatinskih i slavonskih štokavskih pisaca djelatna tijekom 17. i 18. stoljeća, a među njima se posebno ističu franjevci i isusovci čija je praksa usklađena sa zadacima protureformacije i katoličke obnove, ne smijemo zanemariti ni tamošnju sliku razvoja štokavskoga književnog jezika (usp. Vulić 2013: 95161; Farkaš Brekalo 2013: 163-219; Lukić, Blažević Krezić 2014: 151-171). Početak kajkavskoga književnog jezika izravno je povezan s izdavačkotiskarskom djelatnošću Jurja Zrinskoga, odnosno s njegovom tiskarom u Nedelišću u kojoj je 1574. otisnuta najstarija kajkavska knjiga - feudalni zakonik Decretum Ivana (Ivanuša) Pergošića.

Već smo istaknuli da su se vrsni poznavatelji hrvatske književnojezične povijesti tijekom posljednjih triju stoljeća bavili (i bave) sustavnim istraživanjem protestantske stilizacije, nastojeći rastaviti taj jezični složenac na proste faktore - provođenjem usporedne jezične analize otisnutih

4 Njegovim su se zamislima isprva inspirirali i reformatori glagoljskih liturgijskih knjiga u 17. stoljeću - I. T. Mrnavić, F. Glavinić, R. Levaković.

5 Kapetanić međutim napominje da naddijalektna sjeverna čakavština 16. stoljeća nije bila izravno povezana s protestantskom vizurom hibridnoga tipa književnoga jezika (2011: 83). 
protestantskih naslova, razmatranjem njihove povezanosti s crkvenoslavenskim predlošcima ${ }^{6}$ i hrvatskom lekcionarskom tradicijom ${ }^{7}$, a najzad i prepoznavanjem tragova inojezičnih protestantskih izdanja koja su našim prevoditeljima poslužila kao polazište. ${ }^{8}$ Istraživanja su ih usmjerila na podcrtavanje općih značajki njihova dinamična, demokratična i mješovita jezika - s neupitnom čakavskom osnovicom koja je podvrgnuta utjecaju slovenskoga i crkvenoslavenskoga jezika, kako između djela tako i unutar pojedinih izdanja. Poznato je da su Trubarovi slovenski predlošci - tzv. polazište za hrvatske reformatore (uz latinske, njemačke i inojezične predloške) - u njihovoj prevoditeljsko-uredničko-korektorskoj djelatnosti ostavljali tzv. slučajan trag (primjerice Trubarov prijevod Novoga testamenta, odnosno njegovi Artikuli, usp. Eterović 2016: 381). ${ }^{9}$ S druge pak strane, utjecaj crkvenoslavenskoga jezika promatran je kroz prizmu svjesno i sustavno oblikovanih jezičnih naputaka o važnosti knjiške tradicije. Spomenute su naputke hrvatski protestanti najprije iznosili i razmatrali, a potom su ih nastojali oživotvoriti u svojim tekstovima, oslanjajući se na reprezentativna djela poput Prvotiska (1483) i Misala Pavla Modrušanina (1528). Odluka o uvažavanju knjiške tradicije ponajprije je vidljiva u grafijskome (fonološkome) konzervativizmu pojedinih protestantskih

6 Primjerice s hrvatskim crkvenoslavenskim Prvotiskom misala iz 1483. te s Misalom Pavla Modrušanina iz 1528. (usp. Polovič 1908: 56-73; Čupković 2010a: 1-36).

7 Usporedo su se analizirali protestantski biblijski tekstovi (zasvjedočeni u gNt1, ćNt, gP, ćP i drugdje) i odabrane sekvencije Lekcionara Bernardina Splićanina (LBS, 1495), odnosno njegova drugog izdanja iz 1543. (tzv. Zborovčićev lekcionar), pa i rukopisnoga dubrovačkog Lajpciškog lekcionara (Ll), napisanog između 1550. i 1570. Na tekstološku (i inu) bliskost spomenutih predložaka ukazivali su brojni istraživači protestanske književnojezične problematike počevši s Augustom Leskienom i Milanom Rešetarom (vidi: Fancev 1916a: 157-158; Jembrih 2007: 27-28; Polovič 1908: 56-73; Čupković 2010a: 1-36; Eterović 2018: 73-98; Žagar 2019 i dr.).

8 Poznato je kako su o jeziku naših ranonovovjekovnih protestantskih izdanja - kao glavni urednici tekstova i prevoditelji njemačkih, latinskih, talijanskih, čeških i slovenskih izvornika - skrbili Stipan Konzul Buzećanin i Anton (Antun) Dalmatin, uz svesrdnu pomoć suradnika iz Istre i Primorja, npr. Jurja Cvečića i Ivana Lamelle iz Pazina, Matije Pomazanića iz Berma, Mateja Živčića i Ivana Fabijanića iz Pazina, Frane Hleja/Kleja iz Istre, Jurja Juričića iz Vinodola, Leonarda Merčerića iz Cresa, Grgura Vlahovića iz okolice Metlike i drugih. Ne treba zaboraviti ni na djelatnost uskočkih pravoslavnih svećenika - Ivana/Jovana Maleševca iz Bosne i Matije Popovića iz Srbije - koji su nekoliko mjeseci boravili u Urachu (krajem 1561. te na samome početku 1562, usp. Žagar 2019).

9 Hrvatski reformatori ističu da su iz kranjskoga prevodili Novi Testament, Razumne nauke, Artikule i Postilu, a to vrijedi i za Katekizam i Abecedarij (Vidic 1898: 113-129; Murko 1925: 75). 
izdanja, a potom i u jezičnim obilježjima leksičke, morfološke i sintaktičke razine opisa, napose ćiriličnih tekstova - iako na umu treba imati različitu jezičnu narav - primjerice - njihovih predgovora i biblijskih ulomaka. ${ }^{10}$

Podjednako važan zadatak hrvatskih reformatora, ako ne i najvažniji, ticao se sustavnoga osiguravanja razumljivosti i komunikativnosti posredovanih tekstova. Srećom, to nismo u stanju potvrditi tek modernom filološkom analizom njihovih ostvaraja, što znači da zaključke do kojih spomenutom istraživačkom radnjom dolazimo možemo usporediti sa sastavnicama žive rasprave o jezičnome uređivanju tekstova koju su protestanti rado pokretali - bilo u predgovorima svojih izdanja ili u probnim otiscima, bilo u prepisci - reagirajući zapravo na kritike koje je, primjerice, primilo izdanje prvoga dijela glagoljskoga Novog testamenta iz 1562, odnosno ispitujući stanje na terenu (usp. Bratulić 1983: 48; Jembrih 2006: 35-67; 2013: 520-527, Damjanović 2014: 137-138; Kuštović 2016: 246). Novim je knjigama, i pomno razvijanoj književnojezičnoj koncepciji uščuvanoj između korica njihovih glagoljičnih, ćiriličnih i latiničnih izdanja, trebalo zajamčiti aktivan život, potvrdu korisnika razasutih diljem golema teritorija (od slovenskih predjela, kojima su služili Trubarovi prijevodi, pa sve do Carigrada). Znademo da su zahtjevima probitačne novovjekovne vernakularne pismenosti Stipan Konzul Buzećanin i Anton (Antun) Dalmatin doskočili odabirom čakavske osnovice ${ }^{11}$, ali su naslojena i svjesno uključena štokavska jezična obilježja zamjetna od samoga početka (Matešić 1992: 12; Čupković 2010a: 6-11; Žagar 2018: 213-224; Eterović 2018: 7398). Tumače se kao protostandardni ili predstandardni izbojci fonološkoga i morfološkoga sloja, uočeni u prvome dijelu glagoljskoga Novog testamenta (npr. što, tko, sav, u nasuprot oblicima čto, kto, v(a)s, v(a); neutralni čakavski i štokavski - oblici koih, koji, koû nasuprot oblicima kih, ki, ku; nastavak -om u I jd. glavne promjene ženskoga roda nasuprot nastavku -u itd.). Nadalje, u protestantska su izdanja uvrštena i jezična obilježja

10 Počevši s glagoljičnom i ćiriličnom Postilom, knjigama otisnutima 30. listopada 1562. i 1. siječnja 1563, uključujući dakako i ćirilični Novi testament, otisnut 4. svibnja 1563. (vidi: Fancev 1916a: 154; Bučar, Fancev 1938: 80; Čupković 2010a: 19; 2013: 138; Damjanović 2014: 130-139; 2018: 110-119; Kuštović 2014: 127, 2016: 246; Žagar 2018: 213-224; Eterović 2018: 75-79; Blažević Krezić, Kuštović, Žagar 2019).

11 Ne samo one čakavštine koju, s obzirom na podrijetlo prevoditelja i urednika hrvatskih protestantskih knjiga, nazivamo organskom (jezik istarskih i sjevernodalmatinskih čakavaca 16. stoljeća) nego i južnije čakavštine koja je mogla biti poduprta lekcionarskim predlošcima (Murko 1925: 74-75; Žagar 2019). 
slovenskoga odnosno kajkavskoga predznaka, a buduća ih istraživanja tek trebaju odrediti kao konkretne slovenizme i/ili kajkavizme (usp. Jembrih 2008: 85-86; Čupković 2013: 139). ${ }^{12}$

\section{Cilj i korpus istraživanja}

Istraživanje je usredotočeno na pronalazak i opis grafijskih / fonoloških sličnosti i razlika između glagoljičnoga i latiničnoga izdanja hrvatske protestantske Spovidi (1564). Dobivene rezultate namjeravamo usporediti sa stanjem zatečenim u ostalim izdanjima hrvatsko-uraške (i regensburške) protestantske tiskare (1561-1565/1568), prateći smjernice istraživača okupljenih na projektu Hrvatske zaklade za znanost pod nazivom Jezik izdanja hrvatske protestantske tiskare u kontekstu književnojezičnih smjernica XVI. stoljeća (Mateo Žagar, voditelj, Stjepan Damjanović, Tanja Kuštović, Ivana Eterović, Blanka (ekovići ${ }^{13}$ ), odnosno referirajući se na rezultate poduzetih jezičnih analiza, poglavito onih koje su motrile grafiju i jezik Spovidi srodnih / bliskih protestantskih izdanja: glagoljičnih i ćiriličnih Artikula iz 1562. (usp. Ceković 2016: 41-56; Eterović 2016: 379-407; Kuštović 2017: 91-112; Damjanović 2017: 141-148; Žagar 2016: 585-606), a potom i glagoljične, ćirilične i latinične Postile iz 1562, 1563. i 1568. (usp. Damjanović 2018: 110-119; Blažević Krezić, Kuštović, Žagar 2019). Jezična će se obilježja zacrtanoga korpusa dovoditi u vezu sa značajkama hrvatskoga književnog jezika 16. stoljeća i naddijalektno usmjerenom književnojezičnom koncepcijom hrvatskih reformatora, pri čemu se pozornost svraća na odrednice pismo, vrijeme / prostor, odnosno na smjenu opće jezične politike hrvatskoga protestantskog projekta. Nije dakle nevažna godina objelodanjivanja glagoljične i latinične Spovidi (1564). Budući da nas uvodi u svojevrsnu završnicu njihova prevoditeljsko-izdavačkoga pothvata, razumno je pretpostaviti da će - barem kada je o grafiji i fonologiji riječ - jezična slika Spovidi rasvijetliti sudbinu koncepcijskoga zaokreta uočena u protestantskim izdanjima s kraja 1562. i početka 1563. godine. Podsjetimo, nakon prvoga dijela glagoljičnoga Novog testamenta (12. siječnja 1562) otisnuta je glagoljična, a ubrzo nakon nje

12 Kadšto je nemoguće odrediti dolazi li oblik iz organskoga govora (primjerice kajkavskoga ili čakavskoga), odnosno je li odraz utjecaja slovenskoga jezika na govor prevoditelja ili trag koji ostavlja slovenski književni predložak u prevoditeljevoj djelatnosti (npr. oblik hiža u gNt) (usp. Čupković 2010a: 17).

13 Godine 2017. pridružuje im se i autorica ovoga rada, koji je također oblikovan u okviru spomenutoga projekta. 
i ćirilična Postila (30. listopada 1562. i 1. siječnja 1563). U potonjim se dvjema knjigama jasno razaznaje nova struja redigiranja protestantskih tekstova, očitovana u arhaizaciji grafijskoga i jezičnoga izraza (ćirilskih, ali i glagoljskih izdanja), postupnome uklanjanju štokavskih jezičnih obilježja, uopće izraženome oslanjanju na knjišku tradiciju. Ostaje međutim otvoreno pitanje sustavnosti (dosljednosti) korektora koji su provodili pravopisne i jezične preinake tekstova glagoljične i ćirilične Postile (usp. Damjanović 2018: 114): npr. čuvanje grafema jat: u družbi (gNt1 79B) : v družbê (gP 18v-19v, ćP 20v-21r) : v družbi (ćNt 84A-84B); bilježenje jerovskih znakova: učenik (gNt1 159B) : Učenikb (ćNt 166B-167A, ćP 192r-192v) : učenik' (gP 175r-175v), ot ovih (gNt1 159B) : otb ovihb (ćNt 166B-167A, ćP 192r-192v) : ot' ovih' (gP 175r-175v), mrtva (gNt1 12A) : mbrtva (ćNt 12B) : m'rtva (gP 158v-159r, ćP 175r-175v): martva (1P 994); izbjegavanje derva: jere (gNt1 32B-33A) : jere (ćNt 34A-34B) : ere (gP 155r-155v, ćP 171v-172r); anĵelov (gNt1 107B-108A) : angelov' (gP 101r-101v) : angelovb (ćNt 112B-113A, ćP 111r-112r) : anjelov (1P 643-644); rojen (gNt1 127B-128A) : rojen' (gP 96v-97r) : rojens (ćP 106r-107r) : preporojenb (ćNt 133B-134A) : rojen (lP 629-630) - doduše na tradicionalno opravdanim mjestima, ali napose u bilježenju inicijalnoga i intervokalnoga /j/ kao u primjerima ĵim : imb, tj. j̧ima : ima, što su situacije u kojima se pojava đerva, suprotno prvotnoj / starijoj hrvatskoglagoljskoj tradiciji, može smatrati ustupkom izgovoru (gNt1), dok se izbjegavanje đerva (gP), udruženo s bilježenjem jerovskih znakova, imenuje arhaizacijom grafijskoga izraza, odnosno njegovim usklađivanjem $s$ hrvatskom crkvenoslavenskom normom (i reprezentativnim glagoljičnim predlošcima) (usp. Damjanović 2018, Blažević Krezić, Kuštović, Žagar 2019). Stanje zatečeno u glagoljičnoj i latiničnoj Spovidi (1564) može ponuditi neke nove odgovore, barem kada je riječ o dosljednosti i pripravnosti korektora koji su provodili naznačene intervencije.

U središtu je naše istraživačke pozornosti knjižica koja se u razvedenome žanrovskom sustavu protestantske književnosti određuje kao dogmatsko-katehetsko djelo i teološka rasprava, što Spovid i spoznanje prave krstjanske vire (1564) stavlja uz bok protestantskim Artikulima (glagoljica i ćirilica, 1562), odnosno knjižicama kao što su Razgovaranje meju papistu $i$ jednim luteran(om) (latinica, 1555), Beneficium Christi. Govorenje vele prudno (glagoljica, 1563, latinica, 1565) i Bramba augustanske spovedi (glagoljica i latinica, 1564) ${ }^{14}$ (usp. Jembrih 2006: 38). Mahom je riječ o sasvim novim

14 Prijevod Melanchthonove Apologije Augsburške vjeroispovijesti (lat. Apologia Confessionis Augustanae, 1530/1531). 
protestantskim naslovima, odnosno tekstovima koje hrvatski reformatori nisu mogli prevoditi držeći se starijih hrvatskih (sigurnosnih) predložaka, bilo crkvenoslavenskih, bilo vernakularnih / lekcionarskih.

Potrebno je stoga predstaviti motrene naslove na način koji su polovinom 20. stoljeća inaugurirali Bučar i Fancev (1938: 113-116):

Spovid i spoznanie pravê krstijanske vire ka e prezmožnomu Cesaru Karlu petomu Rimskoga Orsaga ploditel'ju, u Spravišću va Avgusti Zručena u godišću IS(U)H(RS)TA 1530. Sada naiprvo iz Latinskoga i Nimškoga jazika va Hrvatski: Po Antonu Dalmatinu i Stipanu Istrijaninu Istlmačena.

Psal. 119 I govorah' od' svidočastva tvoga pred kralji i ne stidih se.

\section{VTUBINGI 1564.}

Naslovni je list glagoljičnoga izdanja Spovidi uokviren, prati ga 113 obrojčenih listova u formatu $8^{\circ}$, a na samome kraju nalazi se jedan nenumerirani list. Spovid je bila otisnuta u 400 primjeraka. Ulomak K ŠTATCU prostire se na nekoliko uvodnih stranica (1r-3r) donoseći podatke o prvim primjercima Augsbuške konfesije ili vjeroispovijesti (lat. Confessio Augustana) koji nisu bili službeno odobreni, stoga je sastavljeno novo, prošireno i izmijenjeno Melanchthonovo izdanje čiji je prijevod na hrvatski jezik pripremljen i otisnut 1564. u vidu glagoljične i latinične Spovidi (usp. Bučar, Fancev 1938: 113-114; Jembrih 2008: 23). Slijedi PREDGOVOR CESARU KARLU PETOMU (3v-8v) zaključen popisom osoba zaduženih za uređivanje crkvenih odnosa: Ivan Herceg Saksonie Izberitel, Juraj Markio Brandeburski, Ernest Herceg Luneburgski, Filip Lontgrof Esie (Hessen), Ivan Fridrih Herceg' Saksonie, Francisk Herceg' Luneburgenski, Bolf Poglavnik ili Knez od Anolta (Anthalt), Ladan'je Varoša Norimberskoga, Ladan'je Ravtlinsko (Reutlingen). Svi su oni prispjeli u Augsburg odazvavši se prethodno upućenu pozivu cara Karla V. POGLAVNI ARTIKULI VIRE zauzimaju stotinjak listova (9r-113a), a sadržajne se cjeline jasno mogu razlučiti: najprije su raspisani ARTIKULI (njih 20-ak), potom slijede poglavlja OD VIRE, OD DOBRIH DEL, OD KRIVIH OBIČAJ, KA SU VA ZVANSKIH NAREDBAH PROMINENI, OD OBOJEG DELA SAKRAMENTA, OD SPOVEDI, OD RAZBORA JELA I TAKAJŠIH PAPINIH NAREDBAH, OD ZAKONA ILI ŽENITVE POPOV, OD ZAVIRE ILI ZAVITA FRATARSKOGA, OD OBLASTI I MOĆI CRIKVENE. 
Na samome kraju, točnije na stranici $113 v$ te na dijelu neobrojčena lista, urednici se ponovno obraćaju čitatelju (K ŠTATCU) napominjući kako je Augsbuška konfesija ili vjeroispovijest već izdana u hrvatskome prijevodu, glagoljičnim i ćiriličnim slovima ${ }^{15}$, a u novoj se knjizi taj nauk donosi $v^{\prime}$ jednoi kratkoi Summi, uz sljedeću napomenu:

Tako jesmo / ovu sad(a)šnju Knjigu, prez niednoga / prilagan’ja, čisto i verno iz Diačko- / ga jazika, od' beside do beside / istlmačili: Onako kako jest' pokoi- / nomu Rimskomu Cesaru Karolu pe- / tomu bogoljubna spomenut'ja, po rukah' Krstianskih Hercegov', / Poglavic', i ostalih' stanov' / i Varošev' toga svjetoga Rim- / skoga Orsaga u godišću 1530. / Va Avgusti izručena, i suprot / vsega svita sili i suprotivšći- / ni, po milosti i kriposti Božioi / jest' obdržana i naslidovana.

Sastavljajući glasovitu bibliografiju hrvatske protestantske književnosti, Fancev i Bučar (1938: 114-115) opisali su, među ostalima, i latiničnu Spovid iz $1564 .{ }^{16}$ Naslovnica latiničnoga izdanja sadržajem je izjednačena s

15 Misli se na glagoljično i ćirilično izdanje Artikula (1562), odnosno hrvatsko-uraški prijevod Melanchthonove Augsburške konfesije ili vjeroispovijesti (lat. Confessio Augustana, 1530; usp. Confessio variata, 1540) sastavljene na njemačkome i latinskome jeziku. Artikuli predstavljaju prvi prijevod spomenute knjižice na hrvatski jezik. Stipan Konzul i Antun Dalmatin prevodili su Trubarovo slovensko izdanje, objavljeno u svibnju 1562. godine. Istražujući sintaktičke funkcije participa u hrvatskim Artikulima, Ivana Eterović (2016: 379407) potvrdila je da su naši prevoditelji vjerno slijedili slovenski predložak koji je Trubar organizirao kao novu sadržajnu cjelinu, združivši augsburšku, virtemberšku i sasku redakciju Konfesije s Apologijom Augsburške vjeroispovijesti (lat. Apologia Confessionis Augustanae, 1530/1531). Usto, Trubar je osnovnomu tekstu pridružio rubne bilješke s biblijskim citatima / parafrazama, što je praksa koju su preuzeli i naši prevoditelji. Iako sintaktička razina analize pokazuje da su Konzul i Dalmatin vjerno slijedili slovenski predložak, ne smijemo podcjenjivati njihovu prevoditeljsku umješnost i kreativnost (usp. Eterović 2016: 403). Nadalje, Spovid (1564) predstavlja hrvatski prijevod novoga izdanja Augsburške vjeroispovijesti koje je 1540. priredio Philipp Melanchthon. Podsjetimo, sa sadržajem je Konfesije javnost upoznata 25. lipnja 1530. kada su njezini članci pročitani na crkvenome saboru u Augsburgu, odnosno upućeni caru Karlu V. Prošavši kroz određene izmjene i dopune, Konfesija je službeno prihvaćena 1555. godine, također u Augsburgu. Tom prigodom uspostavljen je tzv. Augsburški vjerski mir. Spomenutim djelima i sporazumima nastojalo se urediti poimanje Svetoga Trojstva, sakramenata, pričesti, ispovijedi, crkvene hijerarhije, celibata, posta, pokore, slobodne volje, građanske djelatnosti i drugih pitanja, napose oslikavanjem odnosa prema stavovima i učenju Katoličke Crkve, isticanjem sličnosti i razlika, a potom i iskazivanjem jasne kritike upućene Katoličkoj Crkvi i Papi.

16 Potrebno je također svratiti pozornost na talijanskim jezikom otisnutu Spovid iz 1562. 
glagoljičnom, ali je pod poglavljem REGULA dodana svojevrsna pravopisna i pravogovorna napomena:

Bogoljubni čtace, ovo Hrvac- / ko čtenje Z latinskimi slovmi / pisano, čtati budeš po običaju gla- / golskih slov, kako vidiš va ovom zdola pisanom Eksemplu, tako se ho- / ćeš brzo s tvoim razumom / naputiti, i pravo po ovoi / Ortografii čtati.

Potom su istaknuta pojedina slovna rješenja latinične grafije, a njima su - kao uputa za čitanje - pridruženi glagoljični ekvivalenti (Slika 1.).

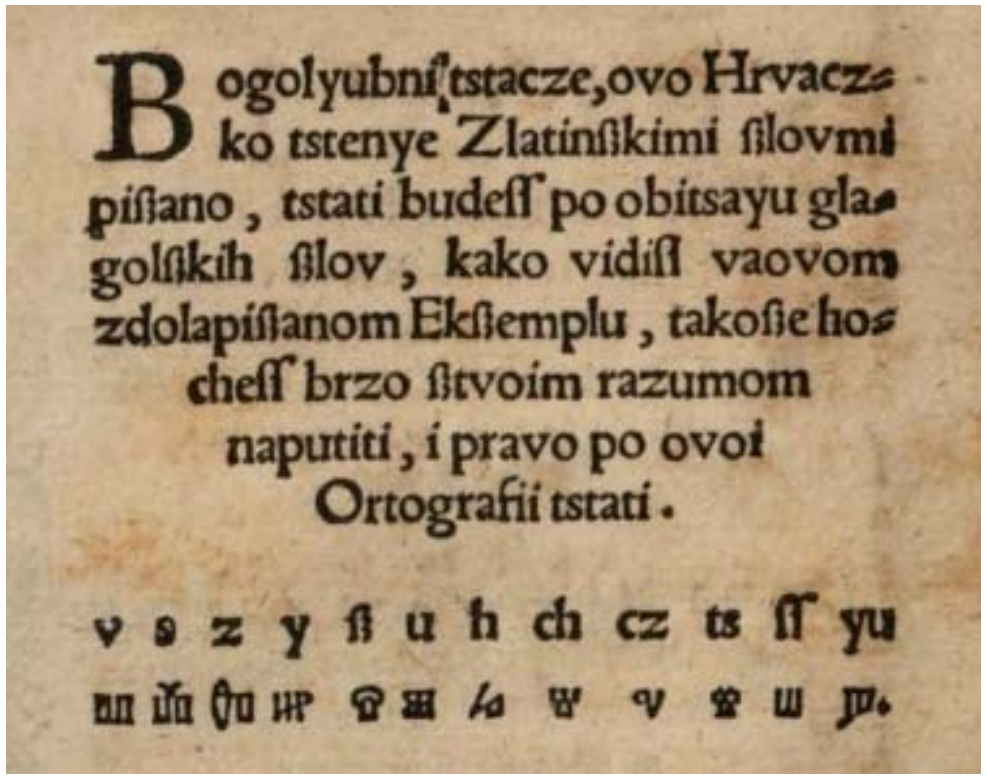

Slika 1. Upute za čitanje latinične Spovidi

Nadalje, Fancev i Bučar (1938: 115) ustvrđuju kako je latinično izdanje sadržajem i strukturom sasvim jednako glagolskome. Knjižica ima 97 obrojčenih listova, iznova donesenih $u$ formatu $8^{\circ}$. Otvara se dvama uvodnim tekstovima (K ČTATCU i PREDGOVOR CESARU KAROLU PETOMU), a zatvara jednim odjavnim (K ŠTATCU). Između njih pronalazimo sve one sadržajne sastavnice izdvojene u opisu glagoljične Spovidi. Popis tiskarskih pogrešaka nije uvršten. Sačuvano je tek nekoliko knjižica latinične Spovidi, a na stranicama zagrebačkoga primjerka nalazi se tzv. Stačićeva bilješka iz 
1647. godine. Iz marginalnih se zapisa također razaznaje da je knjižica bila u vlasništvu Ivana Pridojevića i Nikole Ličkovića.

\section{Grafetička i grafematička obilježja glagoljične i latinične Spovidi (1564)}

Glagoljičnu Spovid odlikuje visokofunkcionalan grafemski sastav, odnosno pismovni izraz prilagođen (fonološkim) potrebama jezika koji fiksira. Mogli bismo ustvrditi da je glagoljična Spovid (1564) preuzela grafetički postav Artikula (1562) i Postile (1562), odnosno njima zacrtanu grafematičku praksu. Namjera je uspostavljene grafijske i fonološke norme bila osigurati razumljivost i čitljivost teksta, istovremeno njegujući afirmativan odnos prema knjiškoj tradiciji, poglavito hrvatskomu crkvenoslavenskom / glagoljskom korpusu. Nekoliko izdvojenih grafetičkih / grafematičkih pojava, poput bilježenja jerovskih znakova, đerva i jata, u stanju su potvrditi istaknuta načela i ciljeve protestanske jezične politike.

\subsection{Bilježenje jerovskih znakova i ostale slovopisne / pravopisne značajke}

Glagoljska Spovid (1564) dosljedno bilježi jerovske znakove: štapić i apostrof, odnosno titlu na mjestu nekadašnjega apostrofa iz hrvatskoglagoljske tradicije. Slično stanje zatječemo u starijim protestantskim izdanjima poput glagoljskih Artikula iz 1562. (usp. Ceković 2016: 44-45; Žagar 2016: 599, 603-604). ${ }^{17}$

17 Apostrofi, koji su se u srednjovjekovnim glagoljičnim tekstovima upotrebljavali kao znak za pisanje jerova (uz štapić), u protestantskim su tekstovima razvili svoje nove oblike, sukladno različitim funkcijama: npr. položenom ravnom crticom ponad slova bilježi se umekšan izgovor (/ń/), a ako je ona postavljena iznad jata - sugeriran je izgovor /ja/, kosom crticom iznad slova $e$ ukazuje se na prejotirani izgovor, a zavijenom crticom (tildom) iznad prvoga suglasnika u suglasničkoj skupini upozorava se na mjesto ispuštena (polu)glasa - pa makar se i ne očekuje njegov izgovor, primjerice uz slogotvorno $/ \mathrm{r} / \mathrm{i} / \mathrm{l} /$, odnosno nakon prijedloga u združenicama (d'rže, v' njih, s'ovu, usp. Žagar 2016: 599). U latiničnome prijepisu glagoljičnoga Novog testamenta nastojalo se ukazati na tu razliku: znak 'označuje štapić, tj. jedan od znakova za stari poluglas, dok se znakom' obilježuje crtica uz slogotvorno /ro i / 1/ (Žagar 2013a: 490, Ceković 2016: 45). U okviru projekta Jezik izdanja hrvatske protestantske tiskare u kontekstu književnojezičnih smjernica XVI. stoljeća također je uvedeno transliteracijsko razlikovanje dvaju ćiriličnih znakova za nekadašnji poluglas: znak ' na mjestu title, odnosno $b$ na mjestu jera. 
Uloga je štapića (i apostrofa / title) - kao znaka za nekadašnji poluglas - u svim glagoljskim protestantskim tekstovima grafetička, bez odraza na fonematskome planu, a k tomu je i neuređena jer se ti znakovi ne pojavljuju na svakoj očekivanoj poziciji (završetak riječi, između suglasnika u riječi te u združenicama, nakon prijedloga) ${ }^{18}$, osobito u prvome dijelu glagoljičnoga Novog testamenta. Slično je s označavanjem slogotvornoga /⿳r / i / / /: u gNt1, gA i gP najčešće susrećemo titlu / crticu postavljenu iznad prethodnoga suglasnika (uz ostala rješenja, npr. u gA pronalazimo i štapić kao i primjere bez jerovskoga znaka, Ceković 2016: 45). ${ }^{19}$

Bilježenje jerovskih znakova na očekivanim (stcsl./hcsl.) pozicijama (gNt1, ćNt, gP, ćP, 1P): kad (gNt1 12A) : kadb (ćNt 12B, ćP 175r-175v) : kad' (gP 158v-159r) : kad (1P 994); njim (gNt 12A) : njimb (ćNt 12B, ćP 175r-175v) : njim' (gP 158v-159r) : $k$ njim (1P 994); jedan (gNt1 12A) : jedanb (ćNt 12B, ćP 175r-175v) : jedan' (gP 158v-159r) : jadan (1P 994); on hip (gNT1 4B) : ons hips (ćNt 4B-5A, ćP 175r) : on' hip' (gP 168r); plav (gNt1 4B) : plavb (ćNt 4B-5A, ćP 175r) : plav' (gP 168r); jedan ot (gNt1 4B) : jedanb otb (ćNt 4B-5A, ćP 175r) : jedan' ot' (gP 168r); Bliznac (gNt1 158A-158B) : Bliznacb (ćNt 165A-165B, ćP 188r) : Bliznac' (gP 170v); osmeh dneh (gNt1 158A-158B) : osmehb dnehb (ćNt 165A-165B, ćP 188r) : osmeh' dneh' (gP 170v); učenik (gNt1 159B) : Učenikb (ćNt 166B-167A, ćP 192r-192v) : učenik' (gP 175r-175v); ot ovih (gNt1 159B) : otb ovihb (ćNt 166B-167A, ćP 192r-192v) : ot' ovih' (gP 175r-175v); mrtva (gNt1 12A) : mbrtva (ćNt 12B) : m'rtva (gP 158v-159r, ćP 175r-175v): martva (1P 994); um'rla (gNt1 12A, gP 158v) : um'rbla (ćP 175r ${ }^{20}$ : umrbla (ćNt 12B) : umarla (1P 994); krvotočiva

\footnotetext{
18 Kadšto se na tim mjestima apostrof bilježi i u latiničnoj Spovidi.
}

19 Damjanović pretpostavlja da je jerovski znak u tome slučaju mogao stajati na mjestu ispuštenoga samoglasnika koji je pratio slogotvoran glas (npr. veržet se : v(b)ržet se, u Ispravcima). Nije međutim sigurno što protestanti žele postići ispuštanjem popratnoga vokala: usklađivanje s izgovorom ili povratak knjiškoj (glagoljičnoj) tradiciji, napominje Damjanović (2014: 120, 144-147). Čini se ipak da teže ostvarenju drugoga od dvaju spomenutih ciljeva (iako jerovski znak / crticu ne postavljaju iza slogotvornoga glasa, kako je to uobičajeno u hrvatskoglagoljskim tekstovima, poglavito liturgijskima, mada i ondje ima potvrda jerovskih znakova ispred /ro i $/ 1 /$, kao i bilježenja slogotvornoga $/ \mathrm{r} / \mathrm{i} / \mathrm{l} / \mathrm{bez}$ znaka za jerove, usp. Gadžijeva i dr. 2014: 69).

20 U ćiriličnoj se Postili zatječu ovakvi slučajevi dvostrukoga bilježenja slogotvornoga /ro/ koji su ispravljeni u ćNt, i to tako da se jerovski znak postavlja samo iza ili ispred slogotvornoga glasa. Iako nismo proveli točno brojenje, analizirani tekstovi iz ćNt ukazuju na brojnost primjera s jerovskim znakom (često i apostrofom) postavljenim ispred sonanta, npr. na stranicama 12B-13A bilježimo sljedeće primjere: umrbla, vrhb, trplaše, mbrtva, 
(gNt1 12A) : krvitečenije (ćNt 12B) : k'rvotočiva (gP 158v-159r, ćP 175r-175v) : karvotočna (1P 994); trplaše (gNt1 12A, ćNt 12B, gP 158v-159r) : t'rpljaše (ćP 175r-175v) : tarpljaše (1P 994) ${ }^{21}$; mrzotu (gNt1 35B-36A) : m'rzotu : (ćNt 37B, gP 162v) : m’rbzotu (ćP 179r); krpajuć (gNt1 4B) : k'rpajuć' (ćNt 4B-5A) : k'rpa'juć' (gP 168r) : k'rpajuć' (ćP 175r); prst moi (gNt1 158A-158B) : p'rsta moga (ćNt 165A-165B); prst' moi (gP 170v) : p'rstb moi (ćP 188r); plt (gNt1 35B-36A) : p'ltb (ćNt 37B, ćP 179r) : p’lt (gP 163r) itd. ${ }^{22}$

Bilježenje jerovskih znakova na očekivanim (stcsl./hcsl.) pozicijama (gS, 1S): Napokon' (gS 88r) : Napokom (1S 75v); neskladnost' (gS 102r) : neskladnost (1S 88r); ali i k'spasen'ju (gS 102r) : k' spasenju (IS 188r); ov' (gS 106r) : ov' (IS 91r), $v^{\prime}$ (gS 110r) : v' (1S 94v) i dr. Ponekad na istoj stranici (unutar istoga izraza) pronalazimo različita rješenja: npr. od' krvi (gS 110r, lS 94v) : od krvi (gS 110r, lS 94v). Za Spovid međutim nisu karakteristični jerovski znakovi uz slogotvorno /ro / i / / /, kako je uobičajeno u Artikulima i u Postili: skrbno (gS 95r, 1S 82v); svršen'je (gS 95r) : svršenie (1S 82v); trpêti (gS 106r) : trpeti (1S 91r); od' krvi (gS 110r, lS 94v); držan’ja (gS 94v) : držania (IS 81v); dlžno (gS 93v, IS 81v), tlmače (gS 49v, IS 95v); v tlmačen'ju (gS 38r, 1S 75r); stlmačene (gS 42r, 1S $82 \mathrm{v})$; tlmačar' (gS 111v, lS 96v). Istražujući pojavu slogotvornoga /1//, odnosno njegovu zamjenu vokalom /u/ u protestantskim tekstovima, Franjo Fancev ustvrdio je kako se ono u starijim izdanjima uraško-hrvatske protestantske tiskare redovito zamjenjuje vokalom $/ \mathrm{u} /$, dok je u knjigama otisnutima nakon isteka 1562. godine učestao povratak slogotvornoga /İ / koji se može tumačiti kao odgovor na kritike upućene jeziku prvoga izdanja glagoljskoga Novog

trbgihb, vbrsti, milosrdbjems (usp. milos'rdbje 5B, Milosbrdie 12A, vidi i: p'lku 82A, pl'no 112B itd.). Damjanović iznosi podatke karakteristične za srednjovjekovni hrvatski ćirilični korpus: npr. u Povaljskoj se listini oba slogotvorna sonanta bilježe prema klasičnome staroslavenskom uzusu $(l b, r b)$, a kada nije tako, znak za jer nalazi se ispred sonanta ili su oni okruženi jerovskim znakovima s obiju strana (plbkb, vrbhb / pblkb, vbrhb / vbrbha itd., 2008: 65).

21 U latiničnoj Postili (1568) slogotvorno / ro / i / / / redovito su zabilježeni uz prateći vokal (usp. Fancev 1916a: 188, 192). Nije međutim sigurno kako se u ostalim protestantskim izdanjima imalo čitati slogotvorno /ṛ/ - budući da njegovo bilježenje s popratnim vokalom $(a, e)$ i nije bilo tako rijetko kao što je ustvrdio Fancev (1916a: 192, usp. Damjanović 2014: 144-147). Taj je zaključak Damjanović iznio na temelju istraživanja provedena na glagoljičnome Katekizmu iz 1561.

22 Usp. i verh nee (gNt1 12B) : vrh' njee (gP 158v) : v'rhs njee (ćP 175r) : vbrhb njeje (ćNt 12B); zvarhu (gNt1 23B) : zvrhu (gP 207r): zv'rhu (ćP 230v): sv'rhu (ćNt 24B); Milosardie (gNt1 11B, gP 224r) : Milos'rdbje (ćP 249r) : Milosbrdie (ćNt 12A); ispuni (gNt1 77A; gP 203r; ćP 226r) : isp'lni (ćNt 81B) itd. 
testamenta, odnosno kao afirmacija knjiške tradicije (usp. Damjanović 2014: 120, 148). U Artikulima je, jednako kao i u glagoljičnoj / ćiriličnoj Postili, slogotvorno / $/ \mathrm{o} /$ uglavnom dosljedno praćeno jerovskim znakom koji se u tekstu glagoljične Spovidi redovito ispušta. ${ }^{23}$ Ondje je, međutim, zabilježena i zamjena slogotvornoga / 1 / slovom $u$ (uglavnom u očekivanim primjerima, usp. Fancev 1916a: 190; Ceković 2016: 45): dužno (gS 34r, lS 68v); tumače (gS 49r, 1S 94r) ${ }^{24}$, ispunjen'ja (gS 93r) : ispunenia (1S 81r) i dr. U glagoljičnoj je Spovidi slogotvorno /r̆/ u neveliku broju primjera zabilježeno uz popratni samoglasnik, dok latinična Spovid na istim pozicijama taj samoglasnik zapisuje ili ispušta: arve (gS 53r) : rve (1S 101v); arvan'ju (gS 31v) : rvanju (1S 63v); Hercegi (gS 114r, 1S 98r); arve (gS 105r, 1S 90v).

Uz naslijeđenu (grafetičku) ulogu jerovskih znakova, u protestantskim tekstovima prepoznajemo novu, s izgovorom itekako povezanu zadaću štapića i apostrofa / title. ${ }^{25}$ Postavljeni ispred slova za pojedine vokale (primjerice $e$ ili $\hat{u}$ ), jerovski znakovi ukazuju na njihov prejotirani izgovor. Također, zaduženi su za označavanje palatalnoga izgovora glasova /1/ i /n/.

Bilježenje prejotiranoga izgovora e ili $\hat{u}$ (gNt1, gP, ćP, lP): npr. 'je u pustinji (gP 163r) ${ }^{26}$, usp. tvoju (gNt1 158A-158B) : tvoju (ćNt 165A-165B, ćP 188r) : tvo'ju (gP 170v); postavi ju (gNt1 158A-158B) : postavi ju (ćNt 165A-165B, ćP 188r) : postavi 'ju (gP 170v); meju (gNt1 159B, ćNt 166b-167A, ćP 192r) : me’ju (gP 175r-175v).

23 Čini se da se u Artikulima i Postili (1562/1563) prelama spomenuta norma bilježenja slogotvornih sonanata /ro i / / /. Funkcionalnija rješenja starijih izdanja postupno se napuštaju, poput zamjene slogotvornoga /1 / vokalom /u/, odnosno bilježenja slogotvornoga /r̆/ bez pratećega jerovskog znaka. S druge pak strane, grafija se otvara tradicionalnim rješenjima, što pokazuju gotovo jednakobrojne potvrde jerovski (ne)označenih sonanata u Artikulima i Postili. U Spovidi su se pak jerovski znaci koji prate slogotvorno $/ \mathrm{r} / \mathrm{i} / \mathrm{l} / \mathrm{u}$ potpunosti napustili, ali su rijetki primjeri njihova bilježenja pratećim vokalom (kao u lP), odnosno zamjene slogotvornoga /1/ vokalom /u/.

24 U latiničnoj je Spovidi kod slijeda tlm zabilježena (nedosljedna) zamjena vokalom $o$ : tumačeno (gS 84v) : tomačeno (1S 72v) (vidi: Fancev 1916a: 191; Ceković 2016: 45).

25 Štapić i apostrof rabili su se kao indikatori jotacije i glasa /j/ i u hrvatskim crkvenoslavenskim tekstovima: npr. dbêk-, dbêval-, žitbe, žitbi, zdravbe, zdravbi, božbi, kozbi, pbetb, ubbenb, arhanbelb, anbelb itd. Većinom se u navedenim primjerima na mjestu jerovskoga znaka pronalazi i slovo $i$, koje je zapravo frekventnije. Usp. označavanje posebnoga $i$ (tzv. napetoga jera) koje se reducira u okolini $j$ + samoglasnik, npr. jerovski znakovi uz slova jat i $\hat{u}$ : bož'̂u, koz'û, pros'êkb itd. (Gadžijeva i dr. 2014: 70).

${ }^{26}$ je u pustinji (gNt1 36A) : je(stb) v pustinji (ćNt 37B) : 'e u pustinji (gP 163r) : jestb u pustinji (ćP 180r). 
Monograf $n$ s natpisanom ravnom crticom način je upisivanja palatalnoga glasa /nj/ i u glagoljičnoj i u ćiriličnoj Postili: ńim (gP 158v, ćP 175r), ńemu (gP 158v, ćP 175r), je u pustińi (gNt1 35B-36A) : je(stb) v pustińi (ćNt 37B) : ‘je u pustińi (gP 163r) : jestb u pustińi (ćP 180r), Pronalazimo i primjere slovnih sveza $n+$ derv za /nj/: odkuplenje (gNt1 29B) : odkupljenbje (ćNt1 30B-31A) : odkuplenje (gP 214v-215r) ${ }^{27}$ : odkuplênbje (ćP 138v-139r). Nema mnogo primjera s neobilježenim palatalnim glasom /nj/: Gospodne (gNt1 34B-35A) : Gospodnje (ćNt 36B) : Gospodne (gP 173v, ćP 191r); negovo (gNt1 159B) : njegovo (ćNt 166B-167A) : ńegovo (ćP 192r-192v, gP 175r-175v). ${ }^{28}$ $\mathrm{Uz}$ monografsko bilježenje palatalnoga glasa $/ \mathrm{nj} /$, prilično je učestao grafemski slijed $n+$ (jerovski znak) $+j(e) / j(a) / j(u)$, odnosno $n+i+$ $j(e) / j(a) / j(u)^{29}$ : razčinen'ja (gNt1 35B-36A) : zapušćenija (ćNt 37B) : razčinen’ja ( $\mathrm{gP} 162 \mathrm{v})$ : razbčinenbja (ćP 179r); navišćenia ( $\mathrm{gP}$ 186r) : navišćenja (ćP 205r); napisanie (gNt1 32B-33A, gP 155r) : napisanbje (ćNt 34A-34B, ćP 171v) : svarhupisanje (1P 978); znamenija (gNt1 35B-36A) : znamenija (ćNt 37B) : znamenja (gP 163r) : znamenbja (ćP 179r); zlameńe (gNt1 158A-158B) : zlamenbje (ćNt 165A-165B) : zlameńe (gP 170v) : zlameńbe (ćP 188r); kamenjem pobiaš (gNt1 34B-35A) : Kamenbjemb pobijašb (ćNt 36B) : kamenjem pobiaš (gP 173v) : kamenjemb pobiašb (ćP 191r); govoreńe (gNt1 159B, gP 175r-175v) : govorenbje (ćNt 166B-167A) : govoreńbje (ćP 192r-192v); na trńe (gNt1 9A-9B, gP 115r-115v, ćP 127v-128r) : na trnbju (ćNt 9B) : na tarnju (lP 752).

27 Monograf e s dijakritikom.

28 Usp. u Spovidi: proklinaju (gS 88r) : proklinaju (1S 76r).

29 Motreći slijedove $t j, d j(<t b j, d b j), s t j, z d j(<s t b j, z d b j)$ te $l j j, n^{\prime} j$, Stjepan Damjanović zaključuje kako kanonski staroslavenski tekstovi češće bilježe grafem $i$ (uz sonante $/ 1 /$ i /n/), što označuje konzervativan način pisanja, dok bilježenje jera predstavlja mlađi način, bliži slivenomu izgovoru. Ta se pak grafijska dvojakost jotativnoga elementa javlja i u hrvatskoglagoljskim tekstovima - npr. poniženie : ponižen'e (vidi: Damjanović 2008: 56). Usp. i tudie (gNt1 4B) : tudbje (ćNt 4B-5A, ćP 175r) : tudie (gP 168r), prišastie (gNt1 35B-36A) : prišastie (ćNt 37B) : prišastije (gP 163r) : prišastbje (ćP 179r), brat’ju (gNt1 159B, gP 175r-175v) : Bratbju (ćNt 166B-167A, ćP 192r-192v), veselije (gNt1 105A-105B, gP 105r-105v) : veselbje (ćNt 110B-111A, ćP 115v-116r) : veselje (1P [674]-[675]). Iz Spovidi izdvajamo: tud'je (gS 100v) : tudie (1S 86v); Bratiju (gS 103r) : Bratju (1S 88v); milosrd'je (gS 93v) : milosrdie (1S 81v). Monograf $n$ češće se rabi za bilježenje spomenutih skupina u glagoljskim protestantskim izdanjima - npr. zlameńe (gNt1 158A-158B) : zlamenbje (ćNt 165A-165B) : zlameńe (gP 170v) : zlameńbe (ćP 188r) (vidi i: Fancev 1916a: 207; Ceković 2016: 53). I u tim se slovnim skupinama monograf ń razmatra kao slovna novina protestantske jezične koncepcije čiji je cilj pojednostavljenje grafemskoga inventara i izgovora teksta. 
U glagoljskoj je Spovidi također učestao grafemski slijed $n+$ (jerovski $z n a k)+j(e) / j(a) / j(u)$, odnosno $n+i+j(e) / j(a) / j(u)$ (potonji je češći u latiničnoj Spovidi): zbrańen'jem' (gS 88r) : zbranenie(m) (IS 76r); ufan'je (gS 93v) : ufanie (1S 80v); zarečen’ja (gS 89r) : zarečenia (IS 78r); svršen’ja (gS 90r) : svršenia (lS 78v); zavezan’je (gS 93r) : zavezanie (1S 80r); činenie (gS 91r) : činenje (1S 79v); odazvanija (gS 91r) : odazvanja (1S 79v); izgovorenie (gS 92r) : izgovorenje (1S 80v); odpušćen'je (gS 93r) : odpušćenie (IS 80r); ispuńen’ja (gS 93r) : ispunenia (1S 80r); zasidan'ja (gS 102r) : zasidania (1S 88r); govorenie (gS 103r) : govorenje (1S 88v); mnan'je (gS 107r) : mnanie (1S 91v); držan’je (gS 107r) : držanie (1S 91v); silovan'je (gS 107r) : silovanie (1S 91v).

Pronalazimo također monograf $n$ s natpisanom ravnom crticom kao način upisivanja palatalnoga glasa /nj/: zbrańen'jem' (gS 88r) : zbranenie (m) (1S 76r); činahu (gS 88v) : činahu (1S 76r), ne mańkahu (gS 88v) : ne mankahu (1S 76v), mańe (gS 88v) : mane (1S 76v), vgańajuć (gS 89r) : vganajuć (1S 76v); smutńe (gS 89v) : smutne (1S 78r); Kńigah' (gS 89v) : Knigah (1S 78v); zarečeńe (gS 91r) : zarečene (1S 79r); promińaju (gS 111v) : p(ro)minaju (1S 96r).

Nadalje, u ćiriličnoj Postili (te u ćNt, rijetko i u glagoljskim tekstovima) pronalazimo monografsko $l \mathrm{~s}$ natpisanom crticom kao način upisivanja palatalnoga glasa /lj/, uz otprije poznata rješenja: neobilježena umekšanost, slovo $l$ praćeno slovom $\hat{u}$, jerovskim znakom, slovom e s dijakritičkim znakom ili jatom (s crticom za /ja/, bez crtice za /je/) (usp. Fancev 1916a: 161): nevola (gNt1 35A-36A), nevola (ćNt 37B, ćP 179r) : nevola (gP 162v); glas ovi po zemli onoi (gNt1 12A) : glasb ovi po vsoi zemli onoi (ćNt 12B) : glas ovi po svoi zemli onoi (gP 158v) : glasb ovi po vsoi zemli onoi (ćP 175r) : glas ovi po vsoi onoi zemlji (lP 994-995); skupla (gNt1 34B-35A) : skuplja (ćNt 36B) : skupla (gP 173v) : skupla (ćP 191r); ljublaše (gNt1 159B, gP 175r-175v): ljubljaše (ćNt 166B-167A) : ljubl’aše (ćP 192r); odkuplenje (gNt1 29B) : odkupljenbje (ćNt 30B-31A) : odkuplenje (gP 214v-215r) : odkuplênbje (ćP 138v-139r).

U glagoljičnoj Spovidi također uočavamo različita slovna rješenja za upisivanje palatalnoga glasa /lj/: a) neobilježena umekšanost: bole (gS 88v) : bole (1S 76r) ${ }^{30}$, preztavlaju (gS 93v) : preztavliaju (1S 80v); prestavlaju (gS 93v)

30 Usp. bolê (gS 90r) : bole (1S 78v). Stjepan Damjanović (2014: 144) problem razmatra u fonetičkome svjetlu, tvrdeći kako je posrijedi depalataliziran slovenski / kajkavski izgovor (navodi primjere volno, na zemli, vola, kluči, kralestva zabilježene u glagoljičnome Katekizmu iz 1561). Na drugom pak mjestu navodi mogućnost „neobilježene mekoće” koju povezuje s 
: prestavlaju (1S 80v); pristavlahu (gS 88v) : pristavlahu (1S 76r), skuplahu (gS 90r) : skuplahu (1S 78v), zmišlaju (gS 90r) : zmišlaju (1S 78v), Krala (gS 91r) : Kralia (1S 79v); b) uz slovo $l$ dolazi slovo $\hat{u}$, jerovski znak, e s dijakritičkim znakom ili jat (s crticom za /ja/, bez crtice za /je/): npr. Blagoslovlên' (gS 88r) : Blagoslovlen (1S 76r), zdomišlênu (gS 88r) : zdomišlenu (1S 76r), živlênie (gS 88v) : živlenie (1S 76v); c) monografsko $1 \mathrm{za} / \mathrm{lj} / \mathrm{s}$ natpisanom crticom / titlom: valaju (gS 91r) : valiaju (1S 79r). ${ }^{31}$

Glas /j/ u glagoljskim se (i ćirilskim) izdanjima bilježi na nekoliko načina ${ }^{32}$ : neobilježeno, grafemom $\hat{\jmath}$ (najčešće u gNt1), $i, \hat{u}$, ćir. ju, ja, je, monografom e s dijakritičkim znakom za označavanje skupine/je/, jatom s natpisanom crticom za skupinu/ja/ (bez crtice za /je/33), nerijetko praćenim štapićem postavljenim ispred spomenute slovne novine hrvatskih protestanata: obdržanija (gS 88v) ${ }^{34}$ : obdržania (1S 76v); divojak' (gS 89r) : divojak (1S 76v); Istorija (gS 91r) : Istoria (1S 79v); zaslužen’ja (gS 92v) : zasluženia (1S 80v); zaslužue (gS 89v) : zaslužuje (1S 78r), milosrd'je (gS 93v) : milosrdie (1S 80v); izhajaju (gS 101r) : izhaiaju (1S 87r); jpistvin (gS 66v) : jestvin (1S 79r); ali i ĵistvin' (gS 100r) : gistvin (1S 86r), svojooi (gS 31v) : svojoj (1S 63v-64r);

činjenicom da su glagoljaši suglasnik prije vokala /e/ uvijek umekšavali (Damjanović 2014: 136-137, 157-158).

31 Razvoj protestantske kose crtice, koja se upisuje ponad slova $e$ (za /je/), odnosno vodoravne crtice, upisane iznad slova $l$ i $n$ ( $\mathrm{za} / \mathrm{lj} / \mathrm{i} / \mathrm{nj} /$ ), Mateo Žagar povezuje sa starijim apostrofom, tj. jerovskim i/ili korekturnim znakom (vidi: Žagar 2016: 603-604).

32 Usp. nosećim i doećim (gNt1 35B-36A) : nosećimb i dojećimb (ćNt 37B, ćP 179r) : nosećim i dojećim (gP 163r); Boži (gNt1 32B-33A) : Božbi (ćNt 34A-34B, ćP 171v) : Božii (gP 155e) : Boži (1P 978); Farizei (gNt1 32B-33A, gP 155e) : farisei (ćNt 34A-34B, ćP 171v); ĵere (gNt1 32B-33A) : jere (ćNt 34A-34B) : ere (gP 155r, ćP 171v); iskušuete (gNt1 32B-33A) : iskušuete (ĆNT 34A-34B) : iskušujete (gP 155v, ćP 171v); verh nee (gNt1 12A) : vbrhb njeje (ćNt 12B) : vrh' njee (gP 158v) : v'rhb njee (ćP 175r) : na nju (1P 994-995); Andrea (gNt1 4B) : Andrea (ćNt 4B-5A) : Andreja (gP 168r, ćP 175r). Suglasnik /j/ često je u gNt1 - osobito na početku riječi - zabilježen đervom, a tomu nije tako u glagoljskoj Postili: npr. vij’' (gNt1 158A-158B) : vii (gP 170v) : vii (ćNt 165A-165B, ćP 188r); Ĵerusolime (gNt1 34B-35A) : Jerusolime (ćNt 36B, ćP 191r) : Erusolime (gP 173v); ja (gNt1 34B-35A, gP 173v) : ja (ćNt 36B, ćP 191r); pipliće svoje (gNt1 34B-35A) : Pišćence svoje (ćNt 36B) : pipliće svoje (gP 173v, ćP 191r).

33 U glagoljskoj su Spovidi učestali, gotovo dominantni, primjeri jata za skupinu /ja/ bez natpisane crtice: npr. imijaše (gS 89r); nahaja (gS 89v), zbog čega se grafematička slika Spovidi udaljuje od one uspostavljene Artikulima i Postilom.

34 Jat za glasovnu skupinu /ja/. Jat se javlja i na etimološki neopravdanim pozicijama (među ostalima za /je/): npr. žênitve (gS 90v) : ženitve (1S 79r); sêbe (gS 91v) : sebe (1S 80r); pomišlên'ja (gS 101v) : pomišlenja (1S 87v); preglêdati (gS 101r) : pregledati (1S 87r); sinovê (gS 103r) : sinove (1S 88v); vêliku (gS 103r) : veliku (1S 88v). 
iskažujemo (gS 45v) : iskažujemo (1S 88v-89v), Ĵazikom' (gS 47r) : jazikom (IS 90v-91r), boĵi (gS 96r) : boji (1S 84r), svétih' (gS 106v) : svetih (1S 92r).

U pogledu (ne)obilježenoga / $\mathrm{j}$ / izdvajamo sljedeće primjere : potvren'je (gS 88r) : potvrjenie (1S 75v), est' (gS 88r) : jest (1S 75v), ere (gS 88r) : jere (1S 76r); zvišue (gS 90v) : zvišuje (1S 79r); ne pristoi se (gS 91r) : ne pristoi se (1S $79 \mathrm{v}) ;$ tae (gS 91v) : taie (1S 80r); svoe (gS 91v) : svoje (IS 80r); pridae (gS 92r) : pridaje (1S 80r); oboe (gS 92r) : oboje (1S 80r).

Slovom $i$ prilično je često zabilježen glas /j/: uboistva (gS 88r) : uboistva (IS 76r), divoike (gS 89r) : divoike (1S 76v); Božioi (gS 89v) : Božjoi (1S 78r); Naiprvo (gS 90r) : Naiprvo (1S 78v); mogućoi (gS 91r) : mogućoi (IS 79v); Divoičice (gS 91v) : Divoičice (1S 79v).

Grafemom $\hat{c}$ zabilježen je glas /ć/, a slovna novina protestantskih izdanja - grafem $\hat{c}$ s trima točkicama (preslovljen kurzivirano) - upotrebljava se za bilježenje skupine /šć/, iako supostoji sa slovnim rješenjem šĉ: kršćen’ju (gS 89v) : kršćenju (1S 78r); tašći (gS 93r) : tašći (1S 80r), Kršćen’ja (gS 89v) : Kršćenia (IS 78r); vlašćim' (gS 90v) : vlašćim (IS 79r); odvrići (gS 90v) : odvrići (1S 79r); prašćaju (gS 101r) : prašćaju (1S 87r). ${ }^{35}$

Iako Spovid ukazuje na raznovrsna i neujednačena slovopisna i pravopisna rješenja, s punim se pravom može ustvrditi da preuzima grafemski inventar starijih (glagoljskih, ali i ćirilskih) izdanja, ponajprije Artikula i Postile, dodatno reducirajući jerovske znakove (primjerice uz slogotvorno $/ \mathrm{r} / \mathrm{i} / \mathrm{I} / /)$, odnosno idući u prilog funkcionalnosti, citljivosti i razumljivosti, sa što jednostavnijim / jednoznačnijim odnosom fon(em) : graf(em) (npr. natpisana slova $l$ i $n$, kosom crticom natpisano $e$, jerovski znakovi u ulozi izgovorne pripomoći itd.). U završnici protestantskoga prevoditeljsko-izdavačkoga pothvata neće se ipak zanemariti odnos prema tradiciji, odnosno srednjovjekovnoj i ranonovovjekovnoj glagoljičnoj normi, što potvrđuje prilično dosljedna (grafetička) uporaba jerovskih znakova na pozicijama nekadašnjih poluglasova, ponekad čak i u latiničnoj Spovidi.

35 Usp. godišć (gNt1 12A) : Godišćb (ćNt 12B) : godišć (gP 158v) : godišćc (ćP 175r) : lit (lP 994-995); u skrovišći (gNt1 35B-36A) : v' komori (ćNt 37B) : u skrovišći (gP 163r) : u skrovišći (ćP 179r); pipliće svoje (gNt1 34B-35A) : Pišćence svoje (ćNt 36B) : pipliće svoje (gP 173v, ćP 191r). 


\subsection{Slovo jat i odrazi}

Poznato je da protestantski glagoljični i ćirilični tekstovi uvažavaju grafijsku i jezičnu popudbinu tradicionalnih glagoljičnih spomenika zbog čega, među ostalima, čuvaju slovo jat unatoč činjenici da je ono tijekom druge polovine 16. stoljeća izgubilo svoju posebnu fonemsku / glasovnu vrijednost te da se ponaša kao grafetički fenomen. Podsjetimo, i hrvatska crkvenoslavenska norma čuva slovo jat. ${ }^{36} \mathrm{U}$ reprezentativnim stcsl. i hcsl. tekstovima jat se upotrebljava za pisanje skupina /je/ i /ja/. Bez obzira na to što je izvorna hrvatska crkvenoslavenska norma od samih početaka propuštala jatovske odraze (e/i), njegova posebna glasovna vrijednost i fonološki položaj nisu dovedeni u pitanje. ${ }^{37}$ Isto nam je tako poznato da se stabilnost jata u hrvatskim govorima ne može izjednačiti s njegovom pozicijom u hrvatskim crkvenoslavenskim tekstovima pa čak ni sa situacijom koju zatječemo u vernakularnoj pismenosti (usp. Damjanović 2008: 60; Gadžijeva i sur. 2014: 71).

Protestantski glagoljični i ćirilični tekstovi zadržali su raznovrsnu uporaba jata i njegovih odraza (i/e), što je zasigurno potaknula situacija na terenu (među korisnicima njihovih izdanja). Tradicionalne su uloge promatranih grafema (slovo jat na pretpostavljenim stcsl. i hcsl. pozicijama, stilistički i funkcionalno motivirane zamjene jata grafemima $e$ i $i)$ upotpunjene novim zadaćama - primjerice upotrebljavanjem jata za pisanje skupine /je/ na etimološki neopravdanim pozicijama, uglavnom uz umekšane suglasnike. Nerijetko se iz te nove funkcije jata iščitava utjecaj latiničnih predložaka (Blažević Krezić, Kuštović, Žagar 2019). Iako latinični tekstovi nisu sačuvali jat, ističu se preciznijim / drugačijim bilježenjem izgovora (primjerice palatalnoga glasa /1/ i /n/), pa su - u većini spomenutih slučajeva - mogli potaknuti korektore glagoljičnih i ćiriličnih protestantskih knjiga na uporabu jata (uz ostala slovna rješenja).

I Fancev (1916a: 164; 1916b) je upozoravao da odnos ikavizama i ekavizama zasvjedočenih u protestantskim tekstovima ne odgovara odnosu ekavskih i ikavskih likova u živome govoru protestantskih pisaca. Također

36 U kontinuitetu od 12. do 16. stoljeća, ali i unutar novocrkvenoslavenskoga jezika, kako istočnoslaveniziranoga tipa (17. i 18. stoljeće) tako i obnovljenoga hrvatskog tipa (19. i 20. stoljeće), s ponešto izmijenjenom funkcijom i novim pravopisnim pravilima (na tragu protestantske norme i važećih crkvenoslavenskih gramatika).

37 To mišljenje zastupaju Stjepan Damjanović (usp. 1984: 60, 2008: 60) i Milan Mihaljević (1991: 57-62, usp. i Gadžijeva i dr. 2014: 71-72). 
je ustvrdio da su, unatoč brojnim iznimkama ${ }^{38}$, ekavski oblici brojniji u glagoljskim i ćirilskim izdanjima, za razliku od prevladavajuće ikavice u latiničnim izdanjima. Istaknuto - uz oprez - možemo povezati sa zaključkom Stjepana Damjanovića (2008: 60-61), donesenim u okviru istraživanja provedena na hrvatskoglagoljskom neliturgijskom korpusu 15. stoljeća. Iz njega proizlazi da su ekavizmi glagoljičnih tekstova mogli biti odraz crkvenoslavenske norme (jat kao glas e-tipa), a ne samo čakavskih i kajkavskih govora. ${ }^{39}$ Iako su u protestantskim tekstovima prevagnuli ikavski oblici - i u korijenskim i u gramatičkim morfemima - nisu malobrojne potvrde sačuvanoga jata (npr. D i L jd. a-osnova, L jd. i L mn. o-osnova, dualni jat u završetku imenica srednjega i ženskoga roda, D i L jd. osobnih zamjenica i dr.). Jat je, uz reflekse $i$ i $e$, bogato oprimjeren i u glagoljičnim Artikulima (usp. Ceković 2016: 52).

Među predlošcima usporedne analize ikavski odraz jata najprije i najčešće susrećemo u latiničnoj Postili (1568) i Spovidi (1564), što smo očekivali s obzirom na dosadašnja istraživanja protestantskih tekstova. Ekavski se odraz jata, uz tzv. stari grafem za jat, mogao držati neutralnijim rješenjem od ikavskoga odraza (usp. Damjanović 2014: 119) ${ }^{40}$, pa je bogatstvo različitih grafijskih rješenja - koje okuplja pitanje bilježenja jata i

38 Usp. svidokoval (gNt 163r) : svedokoval (ćNt 173v), licimiri (gNt 22r) : licemeri (ćNt 23v), vira (gNt 22v) : vera (ćNt 23v). Iako su ekavski likovi najbrojniji u glagoljskim izdanjima, svejedno su još uvijek rjeđi od ikavskih (usp. Fancev 1916a: 165). Pišući o jeziku glagoljskoga Katekizma (1561), Damjanović (2014: 157-158) napominje da je ovomu tekstu polazištem bio ikavsko-ekavski čakavski idiom, u kome ikavizmi prevladavaju (u korijenskima i - napose - u gramatičkim morfemima) premda ekavizmi nisu zanemarivi.

39 Stjepan Damjanović (2014: 70, 157-158) upozorava da se - prema glavnini istraživača usmjerenih na proučavanje hrvatskih glagoljičnih tekstova 16 . stoljeća - stari slavenski samoglasnik jat doživljavao kao glas e-tipa, zbog čega je u tim izdanjima -pa i protestantskima - zabilježeno više ekavizama nego što to nalaže pravilo Jakubinskoga i Meyera. S druge pak strane, izraženo oslanjanje na knjišku tradiciju hrvatske je reformatore opremilo znanjem o tradicionalnome izgovoru jata koji je - nema sumnje - ostavio trag u njihovoj jezičnoj koncepciji. Dodajmo i to da su stari pisci slavenski, kao i hrvatski glagoljaši, slovo $e$ često izgovarali kao /je/, što je podatak kojim Stjepan Damjanović nastoji rasvijetliti prisutnost grafema jat u hrvatskim protestantskim izdanjima, brojeći neizmijenjeni jat, premoćne ikavske, potom i ekavske odraze zasvjedočene u korijenu riječi glagoljičnoga Katekizma (1561).

$40 \mathrm{U}$ Artikulima pronalazimo infinitiv peti ili prezentski oblik sedam od glagola sesti, potom oblik nedele ili pridjev tesan. Za korijene se istaknutih riječi može reći da su pretežno ekavski, a slično stanje zatječemo i u mnogim hrvatskoglagoljskim tekstovima 15. stoljeća (kao knjiški element, a ne odraz govora). Drukčije je, napominje Damjanović (2017: 141-148), s onim ekavizmima koji se javljaju u korijenima u kojima je u Artikulima refleks jata domi- 
njegovih refleksa - odraz jezičnih stavova prevoditelja i priređivača protestantskih tekstova, odnosno njihove želje da, s jedne strane, zadrže slovo iz knjiške (crkvenoslavenske) tradicije, napose u glagoljskim i ćirilskim tekstovima, odnosno da urede distribuciju i način bilježenja odraza, pri čemu je slojevita / raznovrsna uporaba ikavizama i ekavizama počesto motivirana stilskim razlozima (usp. Čupković 2010b: 213).

U pogledu bilježenja jata i odraza, glagoljična i ćirilična Postila pokazuju visok stupanj međusobne usklađenosti (uglavnom prema gNt1). Budući da je krajem 1562. / početkom 1563. godine nastupio zaokret prema književnoj (knjiškoj) tradiciji, ne treba nas iznenaditi učestalost staroga grafema jat na stranicama Postile i ćiriličnoga Novog testamenta (i to na etimološki opravdanim pozicijama).

Međutim, čuvanje grafema jat u Postili (gP, ćP) je zabilježeno čak i na mjestima koja su u ostalim tekstovima posvjedočena odrazima: npr. gNt1, IP u družbi, gP, ćP v družbê, ćNt v družbi. Očigledno su dominantne promjene - već spomenuto čuvanje / povećavanje udjela jata s jedne, odnosno bilježenje (ikavskoga) odraza s druge strane - počele ostavljati trag za vrijeme objavljivanja gP i ćP, iako su snažnije promjene koje su zahvaćale biblijski tekst u ćNt nastupile nakon objavljivanja ćP, što izvrsno pokazuje popis jezičnih razlika između gNt i ćNt koji su priredili članovi projekta Jezik izdanja hrvatske protestantske tiskare u kontekstu književnojezičnih smjernica XVI. stoljeća (usp. Blažević Krezić, Kuštović, Žagar 2019). Ne treba međutim s uma smetnuti činjenicu da smo se usmjeravali na ispitivanje stanja u biblijskim (novozavjetnim) protestantskim tekstovima, od kojih se jezik homilija (u gP, ćP, lP) zasigurno razlikuje, baš kao što jezik Artikula i Spovidi nosi svoje posebnosti.

Usporedna analiza glagoljične i latinične Spovidi ukazuje na otprije poznate nijanse bilježenja jata i njegovih odraza (npr. Jembrih 2007: 300314), ilustrirane nizom izdvojenih primjera:

ê : i/e > zavêti (gS 91r) : zaviti (1S 79r), zavête (gS 91v) : zavite (1S 80r), zapovêdi (gS 94a) : zapovedi (1S 82r), vêsti (gS 95r) : vesti (1S 82r), têlesne (gS 97r) : telesne (1S 83v), prepovêdali (gS 100r) : prepovedali (1S 86r), nevêrni (gS 104r) : neverni (1S 90r), têla (gS 105r) : tela (1S 90v), vêčno (gS 110r) : večno (1S 95r)

nantno ikavski, npr. lenost, lep, lepši, mesec, nemški. Njih smijemo povezivati s čakavskim ikavsko-ekavskim govorima, pa čak i sa slovenskim predloškom. 
i : i > zavit (gS 92r) : zavit (1S 80v), odrišiti (gS 91r) : odrišiti (1S 79v), prociniti (gS 91v) : prociniti (1S 80r), nasliduemo (gS 92r) : naslidujemo (1S 80r), grihov (gS 92v) : grihov (1S 80v), grihe (gS 92v) : grihe (1S 80v), gńivu (gS 93v) : gnjivu (1S 80v), povidati (gS 94r) : povidati (1S 82r), naprid' (gS 94v) : naprid (1S 82r), potribno (gS 95v) : potribno (1S 83v), vrimeni (gS 95v) : vrimeni (1S 83v), svidoči (gS 95v) : svidoči (1S 83v), razumili (gS 102r) : razumili (1S 88r), bižati (gS 95v) : bižati (1S 83v), naprid (gS 102r) : naprid (1S 88r), potribno (gS 102v) : potribno (1S 88v), brime (gS 103r) : brime (1S 88v), svit' (gS 102v) : svit (1S 88v), človičaska rič (gS 102v) : človičaska rič (1S 88v), kolinu (gS 102v) : kolinu (1S 88v), svitlost' (gS 103v) : svitlost (1S 89r), riči (gS 104r) : riči (1S 89v), lipim' (gS 104r) : lipim (1S 89v), rišila ni prominila (gS 109v) : rišila ni prominila (1S 94v), svitlost'ju (gS $110 \mathrm{v})$ : svitlostju (1S 95v), prominili (gS 110v) : prominili (1S 95v), povidati (gS 110v) : povidati (1S 95v), odrišenu (gS 113v) : odrišenu (1S 97v), kriposti (gS 114r) : kriposti (1S 98r), beside (gS $114 \mathrm{v})$ : beside (1S 98v)

$e: e>$ večna $(\mathrm{gS} 91 \mathrm{v})$ : večna $(1 \mathrm{~S} 79 \mathrm{v})$, večnoga $(\mathrm{gS} 91 \mathrm{v})$ : večnoga (1S 80r), let' (gS 92r) : let (1S 80r), letom' (gS 92r) : letom (1S 80r), zapovedi (gS 92v) : zapovedi (1S 80v), veru (gS 92v) : veru (1S 80v), dela (gS 93v) : dela (1S 80v), pogibeli (gS 102v) : pogibeli (1S 88v), telesnomu (gS 109r) : telesnomu (1S 93v), krivovernosti (gS 109r): krivnovernosti (1S 93v), razumeti (gS 110v) : razumeti (1S 95v)

i: $e$ > zapovidami (gS 92v) : zapovedami (1S 80v), zapovida (gS $103 \mathrm{r})$ : zapoveda (1S 88v), vire (gS 93r) : vere (1S 80v), vične (gS 97v) : večne (1S 84r), zapovidam' (gS 105r) : zapovedam (1S 90v), zapovidano (gS 107r) : zapovedano (1S 91v), zapovidaju (gS 111r) : zapovedaju (1S 95v), potribno (gS 105r) : potrebno (1S 90v), presvitli (gS 114r) : presvetli (1S 98r)

Iz izdvojena niza doznajemo da prevladavaju ikavski oblici, iako postoje različite kombinacije (usp. Čupković 2010a: 9; Ceković 2016: 46-52; Blažević Krezić, Kuštović, Žagar 2019). 
U odabranome smo uzorku glagoljičnoga teksta Spovidi (88r-113v) nastojali izbrojiti jatovske potvrde i njihove slovne ekvivalente zabilježene u latiničnoj Spovidi. Za razliku od gore istaknutih primjera bilježenja jata (i odraza) na etimološki opravdanoj poziciji (sredina riječi), u nastupajućoj tablici donosimo sve potvrde zabilježena jata, na etimološki opravdanim i neopravdanim položajima, s namjerom isticanja brojnosti potvrda nove funkcije jata, uvedene u glagoljični tekst pod (mogućim) utjecajem latiničnih predložaka. ${ }^{41}$

41 Usp. gS (88r-113v), ukupno 136 potvrda jata, Tablica 1. Latinični predlošci na glagoljične (i ćirilične) mogu utjecati preciznijim bilježenjem izgovora (npr. umekšanih /1/ i $/ \mathrm{n} /$ ). Međutim, iz Tablice 1. vidljivo je da latinična Spovid, barem u izdvojenim primjerima, izgovor ne bilježi precizno. Također, u latiničnoj je Spovidi slovo e prevladavajuće slovno rješenje u odnosu na jat iz glagoljične Spovidi. Nadalje, jatovske potvrde neetimološke skupine razlikujemo s obzirom na novu funkciju jata (bilježenje mekoće prethodnoga suglasnika, uglavnom umekšanoga /l/ > podebljani primjeri), odnosno s obzirom na njihovu slučajnu zastupljenost koja nema veze s prinosima izgovornoj kvaliteti (nepodebljani primjeri). 
Tablica 1. Bilježenje slova jat u protestantskoj Spovidi

\begin{tabular}{|c|c|}
\hline glagoljična Spovid & latinična Spovid \\
\hline \multicolumn{2}{|c|}{ ETIMOLOŠKI NEOPRAVDAN POLOŽAJ } \\
\hline Atêne (gS 101r) & Atene (1S 87r) \\
\hline bêsedami (gS 112r) & besedami (1S 97r) \\
\hline blagoslovlên' (gS 88r) & blagoslovlen (1S 75v) \\
\hline bolê (gS 113v) & bole (1S 78v) \\
\hline bolê (gS 90r) & bole (1S 97v) \\
\hline crikvê (gS 109r) & crikve (1S 85v) \\
\hline crikvê (gS 99r) & crikve (IS 94r) \\
\hline crikvêna (gS 100r) & crikvena (IS 84v) \\
\hline crikvêna (gS 101v) & crikvena (IS 84v) \\
\hline crikvêna (gS 97r) & crikvena (IS 86r) \\
\hline crikvêna (gS 97r) & crikvena (1S 87v) \\
\hline crikvêne (gS 109r) & crikvene (IS 84r) \\
\hline crikvêne (gS 96v) & crikvene (IS 94r) \\
\hline crikvêni (gS 113r) & crikveni (1S 97r) \\
\hline crikvênoga (gS 103v) & crikvenoga (1S 89v) \\
\hline crikvênu (gS 97r) & crikvenu (IS 84v) \\
\hline dalêmu (gS 113r) & dalemu (1S 97r) \\
\hline $\operatorname{dêk}(\mathrm{a}) \operatorname{logu}(\mathrm{gS}$ 110r) & dekalogu (IS 95r) \\
\hline glêdahu (gS 102r) $)^{42}$ & gledahu (1S 88r) \\
\hline Jerêmija (gS 102r) & Jeremia (1S 87v) \\
\hline kralêv' (gS 98v) & kralev (1S 85r) \\
\hline kralêva (gS 112r) & kraleva (1S 96v) \\
\hline kralêvim' (gS 108r) & kralevim (1S 93v) \\
\hline kralêvskoi (gS 112v) & kralevskoi (1S 97r) \\
\hline kralêvsku (gS 111v) & kralevsku (IS 96v) \\
\hline kralêvstva (gS 101v) & kralevstva (1S 87v) \\
\hline kralêvstva (gS 113v) & kralevstva (1S 97v) \\
\hline kralêvstva (gS 96v) & kralevstvo (1S 93r) \\
\hline
\end{tabular}

42 Tzv. umekšano čakavsko l u skupovima kl-, gl-, hl- (gled-, klet-, usp. Fancev 1916a: 200). 


\begin{tabular}{|c|c|}
\hline glagoljična Spovid & latinična Spovid \\
\hline $\begin{array}{l}\text { kralêvstva (gS 98r) } \\
\text { kralêvstvo (gS 107v) } \\
\text { kralêvstvo (gS 111r) } \\
\text { kralêvstvo (gS 98r) } \\
\text { kralêvstvom' (gS 102r) } \\
\text { kralêvstvu (gS 111v) } \\
\text { kralêvstvu (gS 111v) }\end{array}$ & $\begin{array}{l}\text { kralevstvo (1S 96r) } \\
\text { kralevstvom (1S 88r) } \\
\text { kralevstvu (IS 96v) } \\
\text { kralevstvu (IS 96v) } \\
\text { kraljevstva (IS 84r) } \\
\text { kraljevstva (IS 84v-85r) } \\
\text { kraljevstvo (IS 84v-85r) }\end{array}$ \\
\hline mê (gS 98r) & me (1S $84 v-85 r)$ \\
\hline naivêći (gS 96v) & najveći (1S 84r) \\
\hline $\begin{array}{l}\text { narêdba (gS 90v) } \\
\text { narêdbe (gS 109r) } \\
\text { narêdbe (gS 109v) } \\
\text { narêdbi (gS 90v) }\end{array}$ & $\begin{array}{l}\text { naredba (IS 79r) } \\
\text { naredbe (IS 94r) } \\
\text { naredbe (IS 94v) } \\
\text { naredbi (IS 79r) }\end{array}$ \\
\hline $\begin{array}{l}\text { narêena (gS 92v) } \\
\text { narêenih (gS 90r) }\end{array}$ & $\begin{array}{l}\text { narejena (1S 80v) } \\
\text { narejenih (1S 78v) }\end{array}$ \\
\hline $\begin{array}{l}\text { novê (gS 106v) } \\
\text { novê (gS 96v) }\end{array}$ & $\begin{array}{l}\text { nove (IS 84v) } \\
\text { nove (IS 92v) }\end{array}$ \\
\hline obćêne (gS 102r) & obćene (1S 88r) \\
\hline odnimlê (gS 98r) & odnimlje (1S 84v-85r) \\
\hline oslablêna (gS 100v) & oslablena (1S 86v) \\
\hline ostavê (gS 104r) & ostave (1S 89v) \\
\hline platonovê (gS 103v) & platonove (1S 89v) \\
\hline plême (gS 95v) & pleme (1S 83v) \\
\hline $\begin{array}{l}\text { pogublên'ja (gS 102r) } \\
\text { pogublên'je (gS 100v) }\end{array}$ & $\begin{array}{l}\text { pogublenia (IS 88r) } \\
\text { pogublenie (IS 86v) }\end{array}$ \\
\hline pomišlên'ja (gS 101v) & pomišlenja (1S 87v) \\
\hline $\begin{array}{l}\text { posilêni (gS 89r) } \\
\text { posilêni (gS 91v) }\end{array}$ & $\begin{array}{l}\text { posileni (1S 76v) } \\
\text { posileni (1S 80r) }\end{array}$ \\
\hline
\end{tabular}




\begin{tabular}{|c|c|}
\hline glagoljična Spovid & latinična Spovid \\
\hline $\begin{array}{l}\text { postavlên' (gS 108v) } \\
\text { postavlêne (gS 109r) } \\
\text { postavlêni (gS 102v) } \\
\text { postavlêni (gS 109v) } \\
\text { postavlêni (gS 111v) } \\
\text { postavlênim' (gS 109v) } \\
\text { postavlêno (gS 104v) } \\
\text { postavlêno (gS 111r) } \\
\text { postavlêno (gS 90r) } \\
\text { postavlênoi (gS 108v) }\end{array}$ & $\begin{array}{l}\text { postavlene (1S 93v) } \\
\text { postavlene (IS 94r) } \\
\text { postavleni (1S 88v) } \\
\text { postavleni (IS 94v) } \\
\text { postavleni (1S 96v) } \\
\text { postavlenim (1S 94v) } \\
\text { postavleno (IS 78v) } \\
\text { postavleno (1S 90v) } \\
\text { postavleno (1S 96r) } \\
\text { postavlenoi (1S 93v) }\end{array}$ \\
\hline preglêdati (gS 101r) & pregledati (1S 87r) \\
\hline $\begin{array}{l}\text { prestavlênija (gS 100r) } \\
\text { prestavlên'ja (gS 103v) }\end{array}$ & $\begin{array}{l}\text { prestavlenia (1S 86r) } \\
\text { prestavlenia (1S 89v) }\end{array}$ \\
\hline prestuplênie (gS 92r) & prestuplenie (1S 80r) \\
\hline $\begin{array}{l}\text { priimlê (gS 104r) } \\
\text { priimlêmo (gS 94r) }\end{array}$ & $\begin{array}{l}\text { priimle (1S 90r) } \\
\text { priimlemo (1S 81v) }\end{array}$ \\
\hline prileplêna (gS 96r) & prileplena (1S 83v) \\
\hline procinênie (gS ) & procinenie (1S 76v) \\
\hline proglêdaju (gS 101v) & progledaju (1S 87v) \\
\hline $\begin{array}{l}\text { proklêti (gS 108v) } \\
\text { proklêtstvom' (gS 96v) }\end{array}$ & $\begin{array}{l}\text { I prokleti (1S 93v) } \\
\text { prokletstvo(m) (1S 84r) }\end{array}$ \\
\hline prosvitlên'ja (gS 110v) & prosvitlenia (1S 95v) \\
\hline $\begin{array}{l}\text { sê (gS 106r) } \\
\text { sêbe (gS 91v) }\end{array}$ & $\begin{array}{l}\text { se (IS 92r) } \\
\text { sebe (IS 80r) }\end{array}$ \\
\hline sinovê (gS 103r) & sinove (1S 88v) \\
\hline s'krivêna (gS 103r) & skrivena (IS 89r) \\
\hline skušên' (gS 107v) & skušen (1S 93r) \\
\hline slobodšćinê (G jd., gS 110r) & slobodšćine (1S 95r) \\
\hline
\end{tabular}




\begin{tabular}{|c|c|}
\hline glagoljična Spovid & latinična Spovid \\
\hline têre $(\mathrm{gS} 94 \mathrm{v})$ & tere (1S 82v) \\
\hline udobrovolêna (gS 92v) & udobrovoljena (1S 80v) \\
\hline udobrovolêna (gS 94v) & udobrovoljena (1S 82v) \\
\hline umilênstvo (gS 94v) & umilenstvo (1S 82v) \\
\hline vêće (gS 113r) & veće (IS 78r) \\
\hline vêće (gS 89r) & veće (1S 83v) \\
\hline vêće (gS 95v) & veće (IS 97r) \\
\hline vêle (gS 104r) & vele (1S 81v) \\
\hline vêle (gS 111r) & vele (1S 90r) \\
\hline vêle (gS 111v) & vele (1S 96r) \\
\hline vêle (gS 112r) & vele (1S 96v) \\
\hline vêle (gS 94r) & vele (1S 96v) \\
\hline vêliku (gS 103r) & veliku (1S 89r) \\
\hline vêrsu (gS 100v) & versu (1S 86v) \\
\hline volê (gS 110v) & vole (1S 95v) \\
\hline vrimênu (gS 110r) & vrimenu (IS 95r) \\
\hline zdomišlênu (gS 88r) & zdomišlenu (1S 75v) \\
\hline zmišlêna (gS 94v) & zmišlena (1S 82v) \\
\hline zmišlêne (gS 92v) & zmišlene (1S 80v) \\
\hline zmišlêne (gS 95v) & zmišlene (1S 83v) \\
\hline zmišlên'ja (gS 112r) & zmišlenia (1S 97r) \\
\hline zmišlêno (gS 92v) & zmišleno (1S 80v) \\
\hline zmišlêno (gS 94v) & zmišleno (1S 82v) \\
\hline žênitve (gS 90v) & ženitve (1S 79r) \\
\hline živê (gS 105r) & žive (1S 91r) \\
\hline živlênie (gS 88r) & živlenie (1S 75v) \\
\hline živlênie (gS 89r) & živlenie (1S 78r) \\
\hline živlênie (gS 89r) & živlenie (1S 78r) \\
\hline živlên'je (gS 98r) & živlenie (1S 84v-85r) \\
\hline živlên'ju (gS 95r) & živlenju (1S 82v) \\
\hline
\end{tabular}




\begin{tabular}{|c|c|}
\hline glagoljična Spovid & latinična Spovid \\
\hline \multicolumn{2}{|c|}{ ETIMOLOŠKI OPRAVDAN POLOŽAJ } \\
\hline nevêrni (gS 104v) & neverni (1S 90v) \\
\hline prêgovaran'ja (gS 105v) & zagovarania (1S 91r) \\
\hline prepovêdali (gS 100r) & prepovedali (1S 86r) \\
\hline promênjenu (gS 100r) & promenenu (1S 86r) \\
\hline têla (gS 105r) & tela (1S 91r) \\
\hline têlesne (gS 97r) & telesne (1S 84v) \\
\hline têlesne (gS 97v) & telesne (1S 84v) \\
\hline trpêti (gS 106r) & trpeti (1S 92r) \\
\hline vêčno (gS 110r) & večno (1S 95r) \\
\hline vêsti (gS 95r) & vesti $(1 \mathrm{~S} 82 \mathrm{v})$ \\
\hline vêsti (gS 96v) & vesti (IS 84r) \\
\hline zapovêd' (gS 100r) & zapoved (1S 85v) \\
\hline zapovêd' (gS 99r) & zapoved (1S 86r) \\
\hline zapovêdami (gS 106r) & zapovedami (IS 92r) \\
\hline zapovêdi (gS 103v) & zapovedi (1S 81v) \\
\hline zapovêdi (gS 107v) & zapovedi (1S 83v) \\
\hline zapovêdi (gS 94r) & zapovedi (IS 84r) \\
\hline zapovêdi (gS 96r) & zapovedi (IS 85r) \\
\hline zapovêdi (gS 96v) & zapovedi (1S 89v) \\
\hline zapovêdi (gS 98v) & zapovedi (IS 93r) \\
\hline zavête (gS 91r) & zavite (1S 79r) \\
\hline zavêti (gS 91r) & zaviti (IS 79r) \\
\hline
\end{tabular}




\subsection{Bilježenje đerva i ostale grafemsko-fonološke razlike između glagoljične i latinične Spovidi}

Slovo đerv javlja se samo u glagoljskim tekstovima, transliteriramo ga kao $\hat{\jmath}$, a izgovaramo kao /j/. Potvrđuje se u inicijalnoj i postvokalnoj poziciji, kao način bilježenja glasa /j/ bez obzira na podrijetlo. Nadalje, protestanti se đervom služe prilikom upisivanja grčkoga i latinskoga /g'/ (u stranim riječima), odnosno čakavskoga refleksa praslavenske skupine $* / \mathrm{dj} /$, što je svojstveno i hrvatskim crkvenoslavenskim tekstovima (usp. Gadžijeva i sur. 2014: 63-64).

Provedene analize i usustavljena istraživanja potvrđuju izrazitu učestalost đerva u prvome dijelu glagoljičnoga Novog testamenta. Takva se uporaba đerva može protumačiti kao ustupak izgovoru i osviješten iskorak iz okvira najstrože hrvatskoglagoljske pismovne tradicije. Izbjegavanje derva - na tradicionalno opravdanim mjestima, ali napose u bilježenju inicijalnoga i intervokalnoga /j/ (kao u primjeru jim : imb) ${ }^{43}$ - koje je nastupilo u glagoljskom izdanju Postile (1562) s pravom se tumači kao postupak arhaiziranja grafije, odnosno kao obilježje koje potvrđuje usmjeravanje na knjišku (glagoljičnu) tradiciju (usp. Damjanović 2018: 110-119).

U glagoljičnoj se Spovidi slovo đerv prilično često pojavljuje, ali se - već iz nekoliko izdvojenih primjera - uočava njegova prevladavajuća prisutnost na tradicionalno opravdanim mjestima (npr. u stranim riječima). Rijetko se upotrebljava kao metoda upisivanja običnoga glasa /j/: npr. jim' (gS 97r) : im (1S 84v); jakov' (gS 33r) : jakov (1S 66v); stoji (gS 55v) : stoji (1S 105v), zasigurno u manjoj mjeri od one utvrđene u glagoljičnoj Postili (1562). Njegov slovni ekvivalent u latiničnoj Spovidi, uz grafem j, može biti i grafem g, pretežno zabilježen na stabilnim (tradicionalnim) mjestima: Evanĵelsko (gS 89v) : Evangelsko (1S 78r), Evanjeliem' (gS 93v) : Evangeliem (1S 80v); Liturĵiu (gS 56r) : liturgiu (1S 106v-107r); Anĵelske (gS 94v) : Angelske (1S 82r), Anĵel' (gS 104v) : Angel (1S 90r); jistvin' (gS 100r) : gistvin (1S 86r), jistvinami (gS 107r) : gistvinami (1S 91v).

43 Potrebno je razlikovati primjere u kojima se tzv. obično /j/ pojavljuje / zapisuje u inicijalnoj poziciji, konkretno kao protetsko (vjerojatno i čakavsko) /j/ (npr. psl. i stcsl. jimb > imb, čak. im > jim, usp. i gNt1 ĵima život večni : gP, ćP, ćNt, lP ima), od primjera koji potvrđuju bilježenje intervokalnoga /j/ (usp. Damjanović 2009: 370, Vigato 2013: 274; Zubčić 2015: 228). 
Od ostalih upečatljivih razlika između glagoljične i latinične Spovidi, koje su prilično dosljedno zabilježene unutar grafemsko-fonološkog sloja, izdvajamo sljedeće:

- naizmjeničnu uporabu $n: m$ :

Napokon' (gS 92r) : Napokom (1S 80r); brambu (gS 103r) : branbu (1S 88v)

- naizmjeničnu uporabu zamjenica čto i što (čt- : št-):

Čto (gS 63v, 92v) : Što (1S 80r)

- naizmjeničnu uporabu zamjenica kto i tko (kt- : tk-):

kto (gS 32r) : tko (1S 64v) 44

- različito bilježenje ispadanja glasova:

hrvatckimi (gS 90r) : hrvackimi (1S 114v); srdca (gS 97v) : srca (1S 84r); nadstoino (gS 95r) : nastoino (1S 82v)

- različito bilježenje asimilacijskih i disimilacijskih promjena:

općenu (gS 97v) : obćenu (1S 84r); znamenue (gS 92v) : zlamenuje (1S 80v), vnozih' (gS 102r) : mnozih (1S 88r); otneti (gS 96v) : odneti (1S 84r), ot (gS 110r) : od (1S 95r), ota (gS 90r) : oda (1S 78v); slušba (gS 92v) : služba (1S 80v), slušbu (gS 104r) : službu (1S 89v); preztavlaju (gS 93v) : preztavliaju (1S 80v), ali i prestavlaju (gS 93v) : prestavlaju (1S 80v); rasut'je (gS 98r): razsutie (1S 84v), rasut'je (gS 102r) : razsutie (1S 88r); isk(a)zu'je (gS 97r) : izkazuje (1S 83v); raskinuti se (gS 102v) : razkinuti se (1S 88v); preztupiti (gS 108v) : prestupiti (1S 93v); raširil' (gS 107r) : razširil (1S 91v) ${ }^{45}$

44 Štokavski su likovi (što, tko) zastupljeniji u latiničnoj Spovidi.

45 Nesklonost bilježenju asimilacijskih i disimilacijskih pojava zamjetnija je u latiničnoj Spovidi. 


\section{Zaključak}

Razmatranjem grafetičkih / grafematičkih značajki glagoljične i latinične protestantske Spovidi (1564) izvodimo zaključak o naslijeđenome grafetičkom postavu i grafemskom / fonološkom inventaru, postavljenom i uređenom u polazišnim protestantskim izdanjima kakva su, primjerice, glagoljični i ćirilični Novi testament (1562/1563), glagoljična i ćirilična Postila (1562, 1563, uz latiničnu iz 1568), odnosno glagoljični i ćirilični Artikuli (1562). Nekoliko izdvojenih pitanja grafemsko-fonološkoga sloja, poput uporabe jerovskih znakova, derva i jata, odaju usklađenost pisma i jezika protestantske Spovidi s načelima njihove naddijalektno usmjerene jezične koncepcije. Ustanovljene razlike i sličnosti $s$ rješenjima zasvjedočenima u Novome testamentu, Postili i Artikulima govore u prilog mijenama koje su zahvatile njihovu jezičnu politiku / koncepciju (zapravo književni jezik 16. stoljeća u cijelosti), postavši zamjetnima u izdanjima otisnutima krajem 1562, odnosno tijekom 1563. godine (nakon izlaska prvoga dijela glagoljskoga Novog testamenta). Spomenuta usmjerenost na knjišku (glagoljičnu) tradiciju supostoji s funkcionalnim rješenjima koja tekst nastoje učiniti čitljivim i razumljivim. Spovid (1564) je otisnuta u pretposljednjoj fazi protestantskoga izdavačko-tiskarskog projekta, usto pripada nizu sasvim novih prijevoda (onih koji se nisu mogli, poput biblijskoga teksta, oslanjati na hrvatske crkvenoslavenske i vernakularne predloške ${ }^{46}$ ), stoga nas ne treba iznenaditi želja njezinih priređivača da tekst učine razumljivim i prohodnim, čineći ustupke izgovoru, odnosno uređujući odnos graf(em) : fon(em). Treba također naglasiti da im je metoda, u nekim pitanjima, sustavnija negoli u starijim Artikulima i Postili, što primjerice potvrđuje način bilježenja slogotvornoga /ṛ/ i / /o/ (u Spovidi nema pratećega jerovskog znaka, za razliku od stanja zasvjedočena u Artikulima i Postili), uz učestalost nove funkcije jata - za upisivanje izgovora /je/ na etimološki neopravdanim mjestima, i prorijeđenu uporabu đerva, koji je uglavnom zadržan na stabilnim, tradicionalnim položajima, dok se obični glas /j/ bilježi alternativnim / konkurentnim slovnim rješenjima.

46 Ponajprije u tekstološkome smislu. 


\section{Izvori}

ćNt = Dalmatin, Anton; Konzul, Stipan. 1563. Novi teštament. Tübingen (Pretisak. 2008. [ur. A. Jembrih], Zagreb - Ljubljana: Teološki fakultet „Matija Vlačić Ilirik“; Narodna in univerzitetna knjižnica).

ćP = Dalmatin, Anton; Konzul, Stipan. 1563. Postila to jest, kratko istlmačenje vsih nedelskihs Evangeliovb i poglaviteih Prazdnikov(b) (...). Tübingen. Sveučilišna knjižnica u Tübingenu: http://idb.ub.unituebingen.de/opendigi/Gi108_qt\#tab=struct\&p=5 (posjet 25. svibnja 2019).

gA = Dalmatin, Anton; Konzul, Stipan. 1562. Artikuli ili deli prave stare krstianske vere, iz Svetoga pisma redom postavleni na kratko razumno složeni i stumačeni [...]. Sada v'novê is' latinskoga, nemškoga i krainskoga jazika va hrvacki verno st'lmačeni. Urach (Faksimilno izdanje glagoljskoga izvornika, latinički prijepis i usporedba s ćiriličkim izdanjem. 2017. [ur. M. Žagar], Zagreb: Nacionalna i sveučilišna knjižnica u Zagrebu, Visoko evanđeosko teološko učilište u Osijeku).

gNt1 = Dalmatin, Anton; Konzul, Stipan. 1562. Novi testament: 1. dio. Tübingen (Latinički prijepis glagoljskog izvornika. 2013. [ur. D. Matak], Zagreb: Adventističko teološko visoko učilište; Filozofski fakultet Sveučilišta u Zagrebu; Školska knjiga).

$\mathrm{gP}=$ Dalmatin, Anton; Konzul, Stipan. 1562. Postila to jest, kratko istlmačenĵe vsih' nedelskih' Evanjeliov' i poglaviteih' Prazdnikov(') (...). Tübingen. Digitalne zbirke Nacionalne i sveučilišne knjižnice u Zagrebu: https://digitalna.nsk.hr/pb/?object=info\&id=15259 (posjet 22. svibnja 2019).

$\mathrm{gS}=$ Dalmatin, Anton; Konzul, Stipan. 1564. Spovid i spoznanie pravê krstijanske vire ka e prezmožnomu Cesaru Karlu petomu Rimskoga Orsaga ploditel'ju, u Spravišću va Avgusti Zručena u godišću IS(U)H(RS) TA 1530. Sada naiprvo iz Latinskoga i Nimškoga jazika va Hrvatski: Po Antonu Dalmatinu i Stipanu Istrijaninu Istlmačena. Tübingen (digitalizirano izdanje: https://books.google.hr/books?id=stpMAAA AcAAJ\&pg=PP216\&lpg=PP216\&dq=Spovid $+\mathrm{i}+$ spoznanie + prave $+\mathrm{krs}$ tienske+vire\&source=bl\&ots $=$ HofJW2AR5S\&sig $=I k S n K 40 w 8 d c \_2 n y$ EswIGY8JWfKw\&hl=hr\&sa=X\&ved=0ahUKEwjn6ba5xZ_XAhWIvBo KHawBAYIQ6AEIJ DAA\#v= on epage \& q=Spovid \% $20 \mathrm{i} \% 20$ spoznanie\%20prave\%20krstienske\%20vire\&f=false, posjet 30. svibnja 2019). 
$1 \mathrm{P}=$ Dalmatin, Anton; Konzul, Stipan. 1568. Parvi del Posztile evanyeliov, koi sze vszaku nedillu po obitsayu otsito ù czrikvi tstu, zatsanszi od Adventa ili Prissasztya do Vazma. Po goszpodinu Ivanu Brencziu tumatseni i predikani. Potle ù Harvaczki yazik iz Latinszkoga verno obrácheni i sztumatseni po Antonu Dalmatinu i Sztipanu Isstrianinu. Regensburg. // Drugi del Posztile, to yeszt, Letni deli Evanyeliov, ki sze od Vazma zatsanssi, dari do Prissasztya otsito ù Czrikvi vszaku Nedilu tstu: Latinszkim yazikom isztumatseni szkrozi potstovanoga musa Goszpodina, Ivana Brenzcia. Potli na Harvaczki yazik po Antonu Dalmatinu i Sztipanu Isztrianinu obrácheni. Regensburg (e-knjiga na zahtjev, Sveučilišna knjižnica u Regensburgu).

$1 S=$ Dalmatin, Anton; Konzul, Stipan. 1564. Spovid i spoznanie prave krsztianszke vere, ka ye prezmosnomu Czesaru Karlu petomu Rymskoga Orsaga ploditelyu, u Szprauisschu Va Augusti zrutsena u godisschu Isukersta 1530. Szada naiprvo iz Latinszkoga i Nimsskoga yazika va Hruaczki: Po Antonu Dalmatinu i Sztipanu Istrianu Istlmatsena. Tübingen (digitalizirano izdanje Bavarske državne knjižnice u Münchenu: https://reader.digitale-sammlungen.de/de/fs1/object/ display/bsb10206655_00019.html, posjet 30. svibnja 2019).

\section{Literatura}

Babič, Vanda (1999) „Vzhodnoslovanizacija hrvaških glagolskih liturgičnih tekstov v 17. in 18. stoletju in oblikovanje značilnih grafičnih sistemov Lekavovićevih izdaj misala in brevirja", Slovo, 47-48-49, 255-284.

Babič, Vanda (2000) Vpliv vzhodne cerkvene slovanščine na hrvaške glagolske tekste $v$ 17. in 18. stoletju, Razprave Filozofske fakultete, Ljubljana.

Barbarić, Vuk-Tadija (2017) Nastajanje i jezično oblikovanje hrvatskih lekcionara, Institut za hrvatski jezik i jezikoslovlje, Zagreb.

Blažević Krezić, Vera, Tanja Kuštović, Mateo Žagar (2019) „Biblijski tekstovi uraških protestantskih izdanja u suodnosu", Zbornik radova s Prvoga međunarodnoga znanstvenog skupa Hrvatski prijevodi Biblije u organizaciji Odjela za kulturu hrvatskoga jezika Hrvatskoga filološkog društva (HFD) i Katoličkoga bogoslovnog fakulteta (KBF) Sveučilišta u Zagrebu (Zagreb, Hrvatska, 26-28. rujna 2018) (u tisku).

Bratulić, Josip (1983) „Pogledi hrvatskih protestanata na književni jezik”, Radovi Zavoda za slavensku filologiju, 18, 43-49. 
Brozović, Dalibor (1978) „Hrvatski jezik, njegovo mjesto unutar južnoslavenskih i drugih slavenskih jezika, njegove povijesne mijene kao jezika hrvatske književnosti”, Hrvatska književnost u evropskom kontekstu, ur. Aleksandar Flaker i Krunoslav Pranjić, Zavod za znanost o književnosti Filozofskog fakulteta Sveučilišta u Zagrebu, Sveučilišna naklada Liber, Zagreb, 9-83.

Bučar, Franjo, Franjo Fancev (1938) „Bibliografija hrvatske protestantske književnosti za reformacije", Starine JAZU, 39, 49-128.

Ceković, Blanka (2016) „Grafematičke osobitosti glagoljičnog izdanja Artikula (1562)", Meandrima hrvatskoga glagoljaštva: Zbornik posvećen akademiku Stjepanu Damjanoviću o 70. rođendanu, ur. Tanja Kuštović i Mateo Žagar, Hrvatska sveučilišna naklada, Zagreb, 41-56.

Corin, Andrew R. (1993) „Variation and norm in Croatian Church Slavonic”, Slovo, 41/42, 155-196.

Čupković, Gordana (2010a) „Književnojezična koncepcija glagoljskoga i ćirilskoga Novoga testamenta iz 1562./1563. Prilog proučavanju razlika", Filologija, 55, 1-36.

Čupković, Gordana (2010b) „Jezik odlomka reformacijskoga glagoljskog Katekizma iz 1561. i glagoljaška književna tradicija”, 209-226.

Čupković, Gordana (2013) „Prilog proučavanju inojezičnih izvora hrvatskoga reformacijskoga prijevoda Novoga testamenta", Croatica et Slavica Iadertina, IX, 1, 137-144.

Damjanović, Stjepan (1984) Tragom jezika hrvatskih glagoljaša, Hrvatsko filološko društvo, Zagreb.

Damjanović, Stjepan (2008) Jezik hrvatskih glagoljaša, Matica hrvatska, Zagreb.

Damjanović, Stjepan (2009) „Staroslavenski i starohrvatski u hrvatskim srednjovjekovnim tekstovima“, Povijest hrvatskoga jezika 1: Srednji vijek, ur. Ante Bičanić, Croatica, Zagreb, 351-403.

Damjanović, Stjepan (2014) Novi filološki prinosi, Matica hrvatska, Zagreb.

Damjanović, Stjepan (2017) „Uvod u filološku analizu protestantskih Artikula (1562.)", Kolo: časopis Matice hrvatske za književnost, umjetnost i kulturu, 27, 1, 141-148.

Damjanović, Stjepan (2018) „Jezične osobine Postile u kontekstu književnojezičnih smjeranja hrvatskih protestanata", Kolo: časopis Matice hrvatske za književnost, umjetnost i kulturu, 28, 3, 110-119. 
Eterović, Ivana (2016) „Sintaktičke funkcije participa u hrvatskim protestantskim Artikulima (1562.)", Rasprave Instituta za hrvatski jezik i jezikoslovlje, XLII, 2, 379-407.

Eterović, Ivana (2017) „O pojedinim problemima izrade rječnika hrvatskoga jezika XVI. stoljeća”, Filologija, 69, 23-41.

Eterović, Ivana (2018) „Sintaktičke razlike između glagoljičkoga i ćiriličkoga izdanja hrvatskoga protestantskog prijevoda Novoga testamenta", Slovo, 68, 73-98.

Fancev, Franjo (1916a) „Jezik hrvatskih protestantskih pisaca 16. vijeka. Prilog historičkoj gramatici jezika hrvatskoga ili srpskoga", Rad JAZU, 212, 147-225.

Fancev, Franjo (1916b) „Jezik hrvatskih protestantskih pisaca 16. vijeka. Prilog historičkoj gramatici jezika hrvatskoga ili srpskoga”, Rad JAZU, 214, 1-112.

Farkaš Brekalo, Loretana (2013) „Štokavski hrvatski književni jezik u 18. stoljeću", Povijest hrvatskoga jezika - 3. knjiga: 17. i 18. stoljeće, ur. Ante Bičanić, Croatica, Zagreb, 163-219.

Fućak, Jerko (1975) Šest stoljeća hrvatskoga lekcionara, Kršćanska sadašnjost, Zagreb.

HCJ (2014) = Gadžijeva, Sofija, Ana Kovačević, Milan Mihaljević, Sandra Požar, Johannes Reinhart, Marinka Šimić, Jasna Vince (2014) Hrvatski crkvenoslavenski jezik, Hrvatska sveučilišna naklada - Staroslavenski institut, Zagreb.

Jembrih, Alojz (2006) „Od uspjeha do izjave 'viel falsch' o uraškom glagoljskom Novom zavjetu”, Prilozi za istraživanje hrvatske filozofske baštine, XXXII, 63-64, 35-67.

Jembrih, Alojz (2007) „Pogovor uz pretisak glagoljičkoga Novoga testamenta (1562./1563.)", Novi testament 1562./1563. (pretisak), ur. Alojz Jembrih, Teološki fakultet „Matija Vlačić Ilirik”, Zagreb, 5-82.

Jembrih, Alojz (2008) „Pogovor uz pretisak ćiriličkoga Novoga testamenta (1563.)”, Novi teštament 1563. (pretisak), ur. Alojz Jembrih, Teološki fakultet „Matija Vlačić Ilirik”, Narodna in univerzitetna knjižnica, Zagreb - Ljubljana.

Jembrih, Alojz (2013) „Pogovor uz pretisak glagoljskoga Novog testamenta (1562)", Novi testament (1562), I. dio. Latinički prijepis glagoljskog izvornika, ur. Dragutin Matak, Adventističko teološko visoko učilište 
- Filozofski fakultet Sveučilišta u Zagrebu - Školska knjiga, Zagreb, 495-531.

Kapetanović, Amir (2011) „Čakavski hrvatski književni jezik”, Povijest hrvatskoga jezika - 2. knjiga: 16. stoljeće, ur. Ante Bičanić, Croatica, Zagreb, 77-123.

Kuštović, Tanja (2014) „Jezik hrvatsko protestantskog ćiriličkog Novog zavjeta (1563.) prema hrvatskoglagoljskoj tradiciji”, Filologija, 62, 115129.

Kuštović, Tanja (2016) „Filološka proučavanja hrvatskih protestantskih tekstova", Meandrima hrvatskoga glagoljaštva: Zbornik posvećen akademiku Stjepanu Damjanoviću o 70. rođendanu. ur. Tanja Kuštović i Mateo Žagar, Hrvatska sveučilišna naklada, Zagreb, 237-259.

Kuštović, Tanja (2017) „Glagolski oblici u izdanju Artikuli ili deli prave stare krstianske vere (1562.)”, Slovo, 67, 91-112.

Lukić, Milica, Vera Blažević Krezić (2014) „Tragom hrvatske ćirilične baštine u Slavoniji”, Filologija, 63, 151-171.

Malić, Dragica (1980) „Pravci razvoja hrvatskoga književnog jezika do ilirskog razdoblja: pokušaj sinteze”, Rasprave: časopis Instituta za hrvatski jezik i jezikoslovlje, 6-7, 1, 141-162.

Matešić, Josip (1992) „O literarno-lingvističkoj koncepciji hrvatskoga protestantizma”, Buzetski zbornik, 17, 11-14.

Mihaljević, Milan (1991) Generativna fonologija hrvatske redakcije crkvenoslavenskog jezika, Odsjek za opću lingvistiku i orijentalne studije Filozofskog fakulteta, Zagreb.

Mihaljević, Milan (2010) „Položaj crkvenoslavenskoga jezika u hrvatskoj srednjovjekovnoj kulturi", Zbornik na trudovi od Megjunarodniot naučen sobir "Sveti Naum Ohridski i slovenskata duhovna, kulturna i pismena tradicija" (organiziran po povod 1100-godišninata od smrtta na sv. Naum Ohridski), ur. Ilija Velev i dr., Univerzitet „Sv. Kiril i Metodij", Skoplje, 229-238.

Murko, Matija (1925) „Nekoliko reči o jeziku srpsko-hrvatskih protestantskih knjiga", Daničićev zbornik, knj. LV, Srpska kraljevska akademija, Beograd - Ljubljana, 72-106.

Polovič, Ivan (1908) „Evangelij sv. Matevža v protestantskem glagolskem „Prvem delu Novoga Testamenta” iz 1. 1562.”, Trubarjev zbornik X, ur. Fran Ilešič, Matica slovenska, Ljubljana, 56-73. 
Tafra, Branka (2011) „Kroatistička standardološka propitivanja”, Slavenski jezici u usporedbi s hrvatskim II, ur. Dubravka Sesar, FF press Filozofski fakultet, Zagreb, 35-49.

Tandarić, Josip Leonard (1993) Hrvatska glagoljska liturgijska književnost Rasprave i prinosi, Kršćanska sadašnjost, Zagreb.

Vidic, Fran (1898) „Nekaj o razmerju slovenskih Trubarjevih spisov k protestantskim hrvatskim knjigam", Letopis slovenske matice za leto 1898., ur. Anton Bartel, Slovenska matica, Ljubljana, 113-129.

Vigato, Ivica (2013) „Čakavski hrvatski književni jezik u 17. i 18. stoljeću”, Povijest hrvatskoga jezika - 3. knjiga: 17. i 18. stoljeće, ur. Ante Bičanić, Croatica, Zagreb, 263-297.

Vulić, Sanja (2011) „Štokavski hrvatski književni jezik”, Povijest hrvatskoga jezika - 2. knjiga: 16. stoljeće, ur. Ante Bičanić, Croatica, Zagreb, 125-187.

Vulić, Sanja (2013) „Štokavski hrvatski književni jezik u 17. stoljeću”, Povijest hrvatskoga jezika - 3. knjiga: 17. i 18. stoljeće, ur. Ante Bičanić, Croatica, Zagreb, 95-161.

Zubčić, Sanja (2015) „Fonološki opis govora Podkilavca”, Hrvatski dijalektološki zbornik, 19, 227-236.

Žagar, Mateo (2013a) „Slovopis i ortografija u glagoljičkom Novom testamentu (1562): načela latiničkog prijepisa”, Novi testament I. dio. Latinički prijepis glagoljskog izvornika, ur. Dragutin Matak, Adventističko teološko visoko učilište, Filozofski fakultet Sveučilišta u Zagrebu, Školska knjiga, Zagreb, 487-494.

Žagar, Mateo (2013b) „Hrvatska pisma i pravopisi u 17. i 18. stoljeću”, Povijest hrvatskoga jezika - 3. knjiga: 17. i 18. stoljeće, ur. Ante Bičanić, Croatica, Zagreb, 343-369.

Žagar, Mateo (2015) „Zadaci i perspektive istraživanja jezika glagoljskih tiskanih izdanja Šimuna Kožičića Benje (uz pripremanje kritičkog izdanja Misala hruackoga)", Jezik Misala hruackoga, Studije o jeziku Misala Šimuna Kožičića Benje (1531.), ur. Mateo Žagar, Hrvatska sveučilišna naklada, Zagreb, 9-24.

Žagar, Mateo (2016) „Grafetički postav glagoljičkog izdanja Artikula (Tübingen/Urach, 1562)", Meandrima hrvatskoga glagoljaštva: Zbornik posvećen akademiku Stjepanu Damjanoviću o 70. rođendanu, ur. Tanja Kuštović i Mateo Žagar, Hrvatska sveučilišna naklada, Zagreb, 585606. 
Žagar, Mateo (2018) „Elementi leksičkog odabiranja u izdanjima hrvatskih protestanata (Urach, 1561-1564): kontekst i metodološke pretpostavke", Hrvatski prilozi 16. međunarodnom slavističkom kongresu, ur. Stipe Botica i dr., Hrvatsko filološko društvo, Zagreb, 213-224.

Žagar, Mateo (2019) „Tipologija jezičnih razlika među novozavjetnim tekstovima hrvatskih protestanata", Zbornik posvećen osamdesetgodišnjici života akademika Stjepana Krasića (u tisku).

SUMMARY

Vera Blažević Krezić

GRAPHETIC AND GRAPHEMATIC FEATURES OF THE PROTESTANT EDITION OF SPOVID (1564)

This paper analyses various graphetic and graphematic features of the Glagolitic and Latin editions of the Croatian Protestant book Spovid (1564). Prominent research questions - the status of letters yer, yat and derv - are interpreted in comparison with the situation observed in older Protestant editions (Artikuli, Postila) and viewed as a contribution to a better understanding of the Protestant language concept and the Croatian literary language in the $16^{\text {th }}$ century.

Key words: Croatian Protestant printing press; literary language; $16^{\text {th }}$ century; Spovid (1564); graphetics and graphematics 